Document downloaded from:

http://hdl.handle.net/10251/123504

This paper must be cited as:

Bermúdez, V.; Ruiz, S.; Novella Rosa, R.; Soto-Izquierdo, L. (2018). Assessment of air management strategies on particulate number and size distributions from a 2-stroke compression-ignition engine operating with gasoline Partially Premixed Combustion concept. International Journal of Engine Research. 1-22. https://doi.org/10.1177/1468087418802706

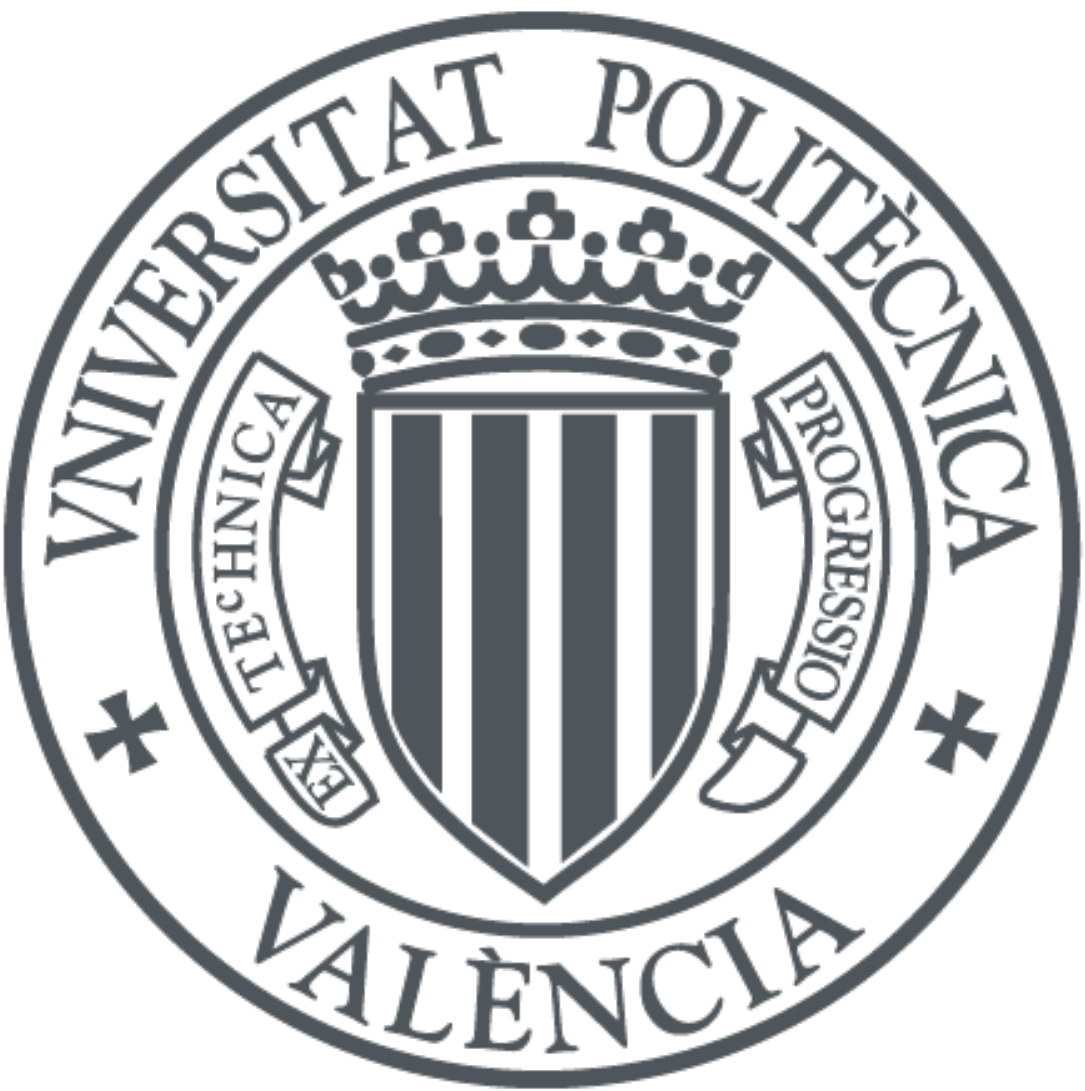

The final publication is available at

https://doi.org/10.1177/1468087418802706

Copyright SAGE Publications

Additional Information 


\title{
Assessment of air management strategies on particulate number and size distributions from a 2-stroke CI engine operating with gasoline PPC concept
}

\author{
Vicente Bermúdez*, Santiago Ruiz, Ricardo Novella and Lian Soto \\ Universitat Politècnica de València, CMT-Motores Térmicos, Camino de Vera s/n, 46022 Valencia, Spain. \\ *Corresponding author. Tel.: +34 96387-9652; E-mail: bermudez@mot.upv.es
}

\begin{abstract}
The newly designed Partially Premixed Combustion (PPC) concept has demonstrated its potential to reduce NOx and particulate matter (PM) emissions combined with highly indicated efficiencies. However, it is highly dependent of the ignition characteristics of the fuel and the air/fuel mixture preparation. Therefore, the proper selection of an injection strategy, of the combustion chamber design and of the air management strategy are critical to ensuring successful PPC operation in the full engine map. The objective of the present investigation consists of evaluating the use of multiple air management strategies over the air/fuel effective equivalence ratio ( $\left.\phi_{\text {eff }}\right)$ and cylinder charge reactivity and its consequent impact on particle number (PN) emissions and particle size distribution. Tests were carried out in a newly designed 2-stroke HSDI CI engine operating with PPC concept using 95 Research Octane Number (RON) gasoline fuel. A Scanning Particle Sizer (SMPS) was used to measure the size distribution of engine-exhaust particles in the range from 6.3 to $237 \mathrm{~nm}$. Three different steady-state operation modes in terms of indicated mean effective pressure (IMEP) and engine speed were investigated. The experiments showed an increase in PN emissions and a progressive shift in the particles size towards larger sizes, increasing the accumulation-mode particles and reducing the nucleation-mode particles with the decreasing of the differential pressure between intake and exhaust $(\Delta \mathrm{P})$ and the valve overlap (OLAP) period. Finally, the particle formation process was limited by the increase in the EGR rate.
\end{abstract}

Keywords: 2-stroke engine; PN emissions; particle size distribution; gasoline PPC concept; air management strategies

\section{Introduction}

Particulate matter (PM) from internal combustion engines (ICE) are often a combination of solid particles and condensed semi-volatile material with different characteristics or properties that vary in size, shape, surface, chemical composition, solubility, and origin. ${ }^{1,2}$ Numerous scientific studies have shown the health problems related to the inhalation of PM emissions. In this regard, it has been shown that respiratory harmful effects caused by exposure to the exhaust gases are attributable more to its particulate content than to its gaseous content. ${ }^{3,4}$ Some cardiovascular and carcinogenic problems are also associated with these particles, specifically with those ultrafine which, due to their size and poor solubility, can pass from the lungs to the bloodstream. ${ }^{5,6}$

The Particle Size Distribution (PSD) is a way of representing the PM emissions, and it usually shows a bimodal structure (nucleation-mode and accumulation-mode). The nucleation-mode represents the particles with sizes of less than $50 \mathrm{~nm}$ in diameter, although some authors define this limit as $30 \mathrm{~nm}^{.79}$ The particles of the above mode are mainly constituted by condensed volatile or semi volatile material and can nucleate to form new particles with a greater mass. ${ }^{1,10}$ The accumulation-mode is formed for non-volatile particles between $30 \mathrm{~nm}$ to $1 \mu \mathrm{m}$ and its chemical composition is of agglomerates of soot with or without volatile material absorbed on the surface. ${ }^{11,12}$ The molecules evolution from vapor-phase or liquid-phase to solid soot particles consists of three stages: nucleation, surface growth and coagulation. ${ }^{13,14}$

Due to the increasing social awareness about human health and environment, the regulations in charge of the limits for the emissions produced by ICEs have evolved significantly. Regarding PM emissions, the latest EU legislations have defined as limit of $6.0 \cdot 10^{11} \# / \mathrm{km}$ for particle number (PN) and $4.5 \mathrm{mg} / \mathrm{km}$ for PM mass. ${ }^{15}$ This reduction of the particle emissions limits has been applied in both spark ignition direct injection (SIDI) and compression-ignition (CI) engines. The PM emissions was always a problem regarding diesel engines. ${ }^{16,17}$ Nevertheless, most recent researches showed that the PM emissions, especially the ultrafine particulates, emitted from direct-injection gasoline (GDI) engines are similar or even higher than diesel engines. ${ }^{18,19}$

Before this situation and in order to increase the engine thermal efficiency, the vehicle manufacturers have heavily invested in the research and development of new combustion concepts. The Homogeneous Charge 
Compression Ignition (HCCI) and Low Temperature Combustion (LTC) are some of these advanced combustion concepts that have been developed, with excellent results in the reduction of nitrogen oxides (NOx) and PM emissions. ${ }^{20-22}$ This is because in both cases, a very long mixing period is required to form a lean and uniform air/fuel mixture, so for early DI strategies it is necessary to inject fuel at a fairly early timing in the initial stages of the compression stroke. If the engine hardware is not carefully optimized for such early timings, a large amount of the sprayed fuel adheres to the wall causing problems of oil dilution and a decline in combustion efficiency ${ }^{23,24}$ and high unburned hydrocarbons (HC) and carbon monoxide (CO) emissions. ${ }^{25,26}$

To solve these problems, research efforts have been shifted towards partially premixed combustion (PPC) concepts, where slightly retarded injection timings compared to HCCI are used to enable partial mixing of the air/fuel mixture, then eliminating over-rich zones where particles are formed, while NOx emissions are reduced by lowering combustion temperatures through the use of large amounts of EGR rates. ${ }^{27-29}$ Therefore, this approach allows operating CI engines in between fully homogenous combustions and full diffusive combustions, where low emissions can be still attained, but while retaining some control over the combustion timing with the injection event.

During PPC operation, different strategies have been investigated in order to promote enough mixing time prior to ignition when high cetane fuels (typical of diesel fuels) were used, the majority of those were focused on a combination of lower compression ratio, swirl level to speed up the mixing process and high fractions of cooled EGR rate to slow down the chemical reactions. However, at high loads, it is difficult to control the combustion process, promoting auto-ignition before reaching the right air/fuel mixture conditions. ${ }^{30,31}$

An additional lever that allows extending the mixing time before the onset of ignition, is to decrease the reactivity of the cylinder charge by using fuels with higher resistance to auto-ignition (low cetane fuels) as is the case of gasoline-like fuels. In the case of gasoline PPC concept, the reported results in terms of emissions and engine indicated efficiencies are far better than those attainable operating with any other advanced combustion concept with diesel fuel. ${ }^{32,33}$ However, there is still an optimum zone in the engine map where the ignition characteristics of a given fuel are better matched to the engine operating condition, which may result in a limited load range for PPC operation depending on the octane number of the fuel. ${ }^{34-36}$ This supposes that the PPC concept typically requires different fuel reactivity, multiple injection strategies and/or advanced valvetrain and EGR systems to ensure proper air charging and ignition control.

In this regard, the 2-stroke engine provides a high flexibility to control the effective equivalence ratio ( $\phi_{\text {eff }}$ ) and internal gas recirculation (IGR) by means of the air management settings, to effectively change the cylinder gas temperature evolution in a much wider range compared to 4-stroke engines. Thus, 2-stroke operation has intrinsically much more potential to adjust the cylinder charge thermochemical conditions and consequently affect the combustion environment, which is a key action to control PM emissions levels in the frame partially premixed combustion concept. This may to extend the load range of premixed combustions, while still keeping maintaining the expected engine performance.

In this framework, the aim of this paper is to experimentally evaluate the impact of different air management strategies over the $\phi_{\text {eff, }}$ IGR ratio and cylinder charge reactivity and its consequent impact on PM emissions from a 2-stroke HSDI CI engine operating with PPC concept and fueled with a commercial 95 Research Octane Number (RON) gasoline. The PN emissions and particles size distribution were analysed in three steady-state operation

modes. For each operation mode, a parametric study was carried out based on the independent modification of three key air management parameters: differential pressure between intake and exhaust $(\Delta \mathrm{P})$, the valve overlap (OLAP) duration and the EGR rate, keeping the fuel injection parameters constant.

\section{Material and methods}

The main characteristics of the engine and the most relevant properties of the gasoline fuel are commented in this section. Additionally, are also presented a detailed description of the different equipment used for pollutants emission measurement, as well as the test methodology.

\subsection{Engine and Fuel Properties}

The experimental studies presented on this investigation were performed on a single-cylinder version of this innovative Renault 2-cylinder 2-stroke poppet valve CI engine with scavenge loop. The single-cylinder engine was specifically designed and manufactured to operate in 2-stroke mode, and it is equipped with a common rail HSDI injection system and a hydraulic variable cam-driven valve timing (VVT) system for controlling both intake and exhaust timing. Detailed specifications of the engine are given in Table 1. 
Table 1. 2-stroke HSDI CI engine main characteristics.

\begin{tabular}{ll}
\hline Characteristic & Value \\
\hline Type & 2-Stroke compression ignition \\
Displacement & $365 \mathrm{~cm}^{3}$ (single cylinder) \\
Number of valves & $4(2 \mathrm{intake} / 2$ exhaust) \\
Bore $\times$ Stroke & $76 \mathrm{~mm} \times 80.5 \mathrm{~mm}$ \\
Connecting rod length & $133.75 \mathrm{~mm}$ \\
Compression ratio & $17.6: 1$ \\
Type of scavenge & Poppet valves with scavenge loop \\
Valvetrain & DOHC with VVT \\
Fuel injection system & Diesel common rail HSDI \\
Injector nozzle & 8 holes, $90 \mu \mathrm{m}, 148^{\circ}$ spray included angle \\
\hline
\end{tabular}

The cylinder head, shown in Figure 1, has four poppet valves with double-overhead camshafts, specifically designed for baffling the flow of air between the intake and exhaust valves, allowing proper scavenging of the burnt gases while keeping short-circuit losses as low as possible during 2-stroke operation. The cylinder head geometry presents a staged roof for baffling the flow of air between the intake and exhaust valves, forcing the air to follow the path of the cylinder wall toward the bottom of the cylinder. This geometry provides the best compromise between scavenging efficiency, acceptable permeability, and convenient combustion chamber geometry. Further information on the engine architecture, boost system requirements, combustion chamber geometry, injection system and scavenging characteristics can be found in previous publication, presented by Tribotte et al..$^{37}$ and Pohorelsky et al. ${ }^{38}$.

\section{[insert Figure 1.]}

The VVT system allowing a flexibility of 30 degrees on both intake and exhaust valve timings independently from the mechanical cam timing. Then, the effective compression ratio, effective expansion ratio and OLAP period between intake and exhaust can be modified by adjusting the valve timing angles. The flexibility of the VVT system is shown in Figure 2, where the intake and exhaust cam lift laws have been included for the reference point of each operation mode studied in this research (Table 3), and also for the two extreme, minimum and maximum, timing positions.

\section{[insert Figure 2.]}

A commercial 95 Research Octane Number (RON) gasoline was used in all the engine tests. The specifications of the fuel properties are provided in Table 2.

Table 2. Gasoline properties.

\begin{tabular}{ll}
\hline Property & Value \\
\hline Research Octane Number & 94.6 \\
H/C ratio & $1.76 \mathrm{~mol} / \mathrm{mol}$ \\
O/C ratio & $0 \mathrm{~mol} / \mathrm{mol}$ \\
Oxygen content & $<0.17 \%(\mathrm{~m} / \mathrm{m})$ \\
$(A / F) s t$ (by mass) & 14.37 \\
LHV & $42.82 \mathrm{MJ} / \mathrm{kg}$ \\
Density (15 C) & $758.1 \mathrm{~kg} / \mathrm{m}^{3}$ \\
Kinematic viscosity $(40 \mathrm{C})$ & $0.44 \mathrm{cSt}$ \\
\hline
\end{tabular}

\subsection{Test bench facilities and fuel used}

The engine was connected to an AC electric dynamometer, which allows engine speed and torque control. The test bench was fully equipped with $\mathrm{K}$ thermocouples and mean pressure sensors in the intake, exhaust, cooling, and lubricating paths. A custom-made low pressure EGR system, designed to provide arbitrary levels of cooled EGR even at very high intake pressures, was added. Figure 3 shows the experimental setup for this study. 
An industrial oil-free screw compressor is used to supply pressurized and filtered intake air to the engine. After the air is compressed and filtered, it passes through intercooler system, where the temperature is lower approximately 220 to $30^{\circ} \mathrm{C}$, before entering a refrigerant air dryer unit, where the air will be dried to remove water vapor. In the 2-stroke configuration with scavenge loop, a positive $\Delta \mathrm{P}$, is mandatory over the complete range of engine speeds to allow the proper scavenging of the burnt gases and minimize the rate of burnt gases which are not expelled out of the cylinder. Therefore, the exhaust backpressure is adjusted by a throttle valve after the exhaust settling chamber, allowing precise control of the $\Delta \mathrm{P}$ across the engine. This procedure allows simulating the operation of a supercharging system under real operating conditions.

Once the air is cooled and dehumidified, its volumetric flow rate is measured by a precision Elster G-100 RVG rotary air flow meter, that provides a measurement ranger between 0.05 to $160 \mathrm{~m}^{3} / \mathrm{h}$ with a precision of $\pm 0.1 \%$ over the measured value. The flow meter integrates pressure and temperature measurements to calculate the air density, and converter the volumetric flow units into mass flow units $(\mathrm{kg} / \mathrm{h})$.

The fuel mass flow was determined by a Dynamic Fuel Balance AVL-733S, that allows getting a direct measurement in the desired acquisition time, keeping very high accuracy (around $0.12 \%$ ). The fuel consumption is determined gravimetrically, which means that the density does not have to be determined. The measurement range of the fuel balance is from $0 \mathrm{~kg} / \mathrm{h}$ to $150 \mathrm{~kg} / \mathrm{h}$.

Measurements of $\mathrm{O}_{2}, \mathrm{CO}, \mathrm{CO}_{2}, \mathrm{HC}, \mathrm{NOx}$ and EGR rate are performed for all the tests by using a Horiba MEXA-7100DEGR gaseous emissions bench. It is composed of different gas analyzers depending on the pollutant: heated flame ionization detector (HFID for HC, heated chemiluminescent detector (HCLD) for NOx, nondispersive infrared detector (NDIR) for $\mathrm{CO}$ and intake and exhaust $\mathrm{CO} 2$ and magneto-pneumatic detection (PMA) for $\mathrm{O}_{2}$. This gas analyzer provides a measurement ranger between 0 to $20 \mathrm{Vol} . \%$ with a precision of $\pm 0.1 \%$ (full scale).

A single-stage dilution system was coupled with a scanning mobility particle sizer (SMPS) to measure PSD. The dilution system used in this study was an MD19-3E Rotating Disk, which uses a unique rotating disk method to dilute a sample for particle measurement. Two disks, one with eight and the other with ten cavities allows to select a dilution ratio from 15:1 to $3000: 1$. A portion of the raw exhaust is captured by each cavity of the rotating disk and is mixed with preheated and filtered dilution air.

In the MD19-3E RD, the dilution unit and the dilution air can be heated up to selectable temperatures of 200 ${ }^{\circ} \mathrm{C}$. This method keeps liquids evaporated above their dew point, during and after dilution, and prevents generation of volatile nanoparticles. This thermal conditioning of the sample allows for the reduction of the concentration range within the acceptable limits of the particle measuring device and provides accurate information on the concentration of particles generated during the combustion process. The advantages of this dilution system can be analyzed in more detail in previous studies by the authors Fierz et al. ${ }^{39}$ and Kasper. ${ }^{40}$

TSI Scanning Particle Sizer (SMPS 3936L75) was used to measure the PSD. This system is equipped with an inertial impactor to remove particles larger than $1 \mu \mathrm{m}$; as well as a Long Differential Mobility Analyzer (LDMA 3081) to select the particle size to be measured, with a range from 2.5 to $1000 \mathrm{~nm}$ and a Condensation Particle Counter (CPC 3775) to count particles with sizes down to $4 \mathrm{~nm}$.

The operating principle of the SMPS is based on the extraction of an original polydisperse aerosol in different monodisperse fractions by separating the particles according to their size as determined by their electrical mobility inside an electrical field (LDMA). Subsequently, the particles of these monodisperse fractions undergo a saturation process, where the butanol condenses on their surfaces, increasing their size and facilitating the detection and counting in an optical detector that provided the particle number per air volume unit $\left(\# / \mathrm{cm}^{3}\right)$ for each particle size (CPC).

To obtain reliable values, the measurement methodology developed by Desantes et al. ${ }^{41,42}$ was used in this study to dilute the exhaust sample and to measure the PSD.

\subsection{Theoretical tools and calculations method}

The main parameters in terms of engine performance, such as IMEP and indicated specific fuel consumption (ISFC), were calculated directly from the measured cylinder pressure and the instantaneous volume. Additionally, the main global combustion parameters, like peak cylinder pressure $\left(\mathrm{P}_{\max }\right)$, maximum pressure gradient $\left(\mathrm{dP} / \mathrm{d} \alpha_{\max }\right)$ and combustion stability indicator (COV $\mathrm{P}_{\max }$ and COV IMEP) were also derived directly derived from the analysis of the cylinder pressure signal.

The rate of heat release (RoHR) and the main combustion angles [(crank angle for 10\% of fuel burnt (CA10) and crank angle for $50 \%$ of fuel burnt (CA50)] are calculated using CALMEC, ${ }^{43,44}$ an in-house internal combustion engine diagnosis software. This model requires different measured instantaneous signals, such as the in-cylinder pressure and the reference pressure at bottom dead center; as well as other engine working conditions (mass flows, 
temperatures). Then the first law of thermodynamics is applied considering the combustion chamber as an open system because of blow-by and fuel injection. It also includes sub-models for considering heat transfer losses, mechanical deformation of the cylinder and blow-by losses.

The EGR rate is calculated from atmospheric carbon dioxide $\left(\mathrm{CO}_{2, \text { atm }}\right)$ and the measured volumetric concentrations of $\mathrm{CO}_{2}$ at the intake $\left(\mathrm{CO}_{2, \text { int }}\right)$ and at the exhaust $\left(\mathrm{CO}_{2, \text { exh }}\right)$, according to the Equation (1).

$$
E G R=\frac{\mathrm{CO}_{2, \text { int }}-\mathrm{CO}_{2, \mathrm{~atm}}}{\mathrm{CO}_{2, \text { exh }}-\mathrm{CO}_{2, \mathrm{~atm}}} \cdot 100
$$

Additionally, a specifically designed procedure based on the tracer gas method ${ }^{45,46}$ was developed to experimentally measure the trapping ratio (TR) in every test point, using methane $\left(\mathrm{CH}_{4}\right)$ as an external gas tracer. First, a controlled concentration of $\mathrm{CH}_{4}$ (around $1000 \mathrm{ppm}$ ) is continuously fed into and mixed with the inlet flow, so the gas divides in the same proportion as the air delivered, when operating at the stabilized engine conditions. The trapped portion of the tracer gas is completely burned in the cylinder during combustion, since the ignition temperature of the tracer gas is much lower than the fuel's ignition temperature. Next, the $\mathrm{CH}_{4}$ concentration has to be measured at the intake $\left(\mathrm{CH}_{4 i n t}\right)$ and also at the exhaust $\left(\mathrm{CH}_{4 \mathrm{xh}}\right)$ manifolds using a dedicated gas analyzer. The sampling probe in the intake side is located at a sufficient distance downstream the addition point, to assure that the tracer/air mixture has been completely homogenized, but upstream the EGR mixing point. In the exhaust side, there is another independent sampling probe placed before the exhaust settling chamber. Finally, the trapping ratio can be determined from the measured methane concentrations according to Equation (2).

$$
T R=1-\frac{Q_{a i r}+Q_{E G R}+Q_{\text {fuel }}}{Q_{E G R}+Q_{\text {air }} \cdot\left(\frac{C_{4 i n t}}{C H_{4 \text { exh }}}\right)}
$$

Where the EGR mass flow rate $\left(\mathrm{Q}_{\mathrm{EGR}}\right)$ is calculated from the EGR rate and the fresh air mass flow rate $\left(\mathrm{Q}_{\text {air }}\right)$, as follows:

$$
Q_{E G R}=Q_{\text {air }} \cdot\left(\frac{E G R}{1-E G R}\right)
$$

The trapping ratio indicates what portion of the delivered flow $\left(\mathrm{Q}_{\mathrm{del}}\right)$ is retained in the cylinder at intake valve closing, the rest being "wasted" in the exhaust, so short-circuiting is naturally equal to (1-TR). Accordingly, the retained $\left(\mathrm{Q}_{\mathrm{ret}}\right)$ and short-circuited $\left(\mathrm{Q}_{\text {short }}\right)$ mass flow rates are obtained from the trapping ratio measurement and the delivered flow, including fresh air and EGR, as follows:

$$
\begin{aligned}
& Q_{\text {ret }}=Q_{\text {del }} \cdot T R=\left(Q_{\text {air }}+Q_{E G R}\right) \cdot T R \\
& Q_{\text {short }}=Q_{\text {del }} \cdot(1-T R)=\left(Q_{\text {air }}+Q_{E G R}\right) \cdot(1-T R)
\end{aligned}
$$

The TR (also known as trapping efficiency) is a measure of the success of trapping the supplied air with a minimum of waste. Therefore, it can also be defined as the retained mass $\left(\mathrm{m}_{\mathrm{ret}}\right)$ divided by the delivered mass $\left(\mathrm{m}_{\mathrm{del}}\right)$.

$$
T R=\frac{m_{\text {ret }}}{m_{\text {del }}}
$$

Once the calculation of the previous parameters has been defined, the effective equivalence ratio $\left(\phi_{\text {eff }}\right)$ and internal gas recirculation (IGR) can be determined. These last two parameters will be used to evaluate the air charging strategy. The $\phi_{\text {eff }}$ is obtained from the stoichiometric air/fuel ratio $\left(\mathrm{AFR}_{\text {stoich }}\right)$ and the in-cylinder air/fuel at intake valve closing (AFR $\mathrm{IVC}$ ), according to the Equation (7).

$$
\phi_{\text {eff }}=\frac{A F R_{\text {stoich }}}{A F R_{\mathrm{IVC}}}
$$

The $\mathrm{AFR}_{\mathrm{IVC}}$ is calculated as the ratio between he usable air retained in the cylinder (excluding the air present in the IGR) and the injected fuel mass $\left(\mathrm{m}_{\text {fuel }}\right)$, as shown in Equation (8). The retained masses of fresh air $\left(\mathrm{m}_{\text {air,ret }}\right)$ and EGR ( $m_{E G R ; r e t}$ ) are known variables obtained from Equations (4) and (5), since the TR is experimentally measured by the tracer gas method at each operating point.

$$
\mathrm{AFR}_{\text {IVC }}=\frac{m_{\text {air,ret }}}{m_{\text {fuel }}}
$$

The IGR is defined as the ratio between the residual gases trapped from the previous combustion cycle and the total cylinder charge trapped at intake valve closing (IVC), as shown in Equation (9). 


$$
I G R=\frac{m_{\mathrm{res}}}{m_{\mathrm{IVC}}}
$$

The total cylinder charge at IVC $\left(\mathrm{m}_{\mathrm{IVC}}\right)$ is calculated according to Equation (10), where the retained mass $\left(\mathrm{m}_{\mathrm{ret}}\right)$ is obtained from Equation (6), since the TR and $\mathrm{m}_{\text {del }}$ is measured experimentally. To estimate the residual gas mass $\left(\mathrm{m}_{\text {res }}\right)$, and accordingly IGR, a calculation method was developed based on the application of two fundamental thermodynamic balances at IVC, the mass balance and the enthalpy balance, according to Equations (10) and (11). The conditions at IVC are the result of combining the conditions of the intake trapped air and the residual gases retained from the previous cycle.

$$
\begin{aligned}
& m_{I V C}=m_{\text {ret }}+m_{\text {res }} \\
& m_{I V C} \cdot h_{I V C}=m_{\text {air,ret }} \cdot h_{\text {air,ret }}+m_{E G R, r e t} \cdot h_{E G R, \text { ret }}+m_{\text {res }} \cdot h_{\text {res }}
\end{aligned}
$$

In addition, all gases and particularly those retained inside the cylinder at IVC are considered ideal. Thus, the system can be expressed through Equation (12). Instantaneous volume at IVC ( $\mathrm{V}_{\mathrm{IVC}}$ ) has been indirectly calculated through the crank slider with pin offset equation, using nominal crank position (angle). Cylinder pressure at IVC $\left(\mathrm{P}_{\mathrm{IVC}}\right)$ is taken from the signal experimentally measured with the piezoelectric pressure transducer, after it has been referenced (pegged) using the BDC absolute pressure. Finally, the specific gas constant of the trapped charge at IVC $\left(\mathrm{R}_{\mathrm{IVC}}\right)$ is assumed to be constant and approximately equal to the value corresponding to fresh air $(287 \mathrm{~J} / \mathrm{kgK})$ for ease of calculation.

$$
P_{I V C} \cdot V_{I V C}=m_{I V C} \cdot R_{I V C} \cdot T_{I V C}
$$

For an ideal thermodynamic process, the specific heats at constant volume $\left(\mathrm{c}_{\mathrm{v}}\right)$ and pressure $\left(\mathrm{c}_{\mathrm{p}}\right)$ are typically assumed to be constant; even when they are pressure and temperature dependent in reality. Accordingly, constant values of $c_{\text {pint }}$ equal to $0.998 \mathrm{~kJ} / \mathrm{kgK}$ and $\mathrm{c}_{\text {pexh }}$ equal to $1.041 \mathrm{~kJ} / \mathrm{kgK}$ are kept for the specific heat capacities of the fresh intake and exhaust gas, respectively, to simplify the calculation at the test bench.

Therefore, by expressing the enthalpy balance as a function of the corresponding heat capacities $\mathrm{cp}$ and temperatures, and operating between Equations (11) and (12), the final expression used to calculate the residual gas mass becomes the Equation (13):

$$
m_{\text {res }}=\frac{C_{\text {pint }}}{C_{\text {pexh }}} \cdot\left(\frac{P_{I V C} \cdot V_{I V C}}{R_{I V C} \cdot T_{\text {res }}}\right)-\frac{C_{\text {pint }}}{C_{\text {pexh }}} m_{\text {air }, \text { ret }} \cdot\left(\frac{T_{\text {air }, r e t}}{T_{\text {res }}}\right)-m_{E G R, r e t} \cdot\left(\frac{T_{E G R, r e t}}{T_{\text {res }}}\right)
$$

To resolve this equation, it is necessary to make the following additional assumptions and simplifications:

- The temperatures of the retained charge $\left(\mathrm{T}_{\text {air,ret }}\right.$ and $\left.\mathrm{T}_{\mathrm{EGR}, \mathrm{ret}}\right)$ before being mixed with the residuals, are assumed to be equal to the mean temperatures measured for the fresh air and EGR flows, while neglecting dynamic heating and heat losses during the induction phase. Next, the in-cylinder charge temperature at IVC results from adding the sensible enthalpies of both the retained and residual fractions, as stated in Equation (10).

- The last and strongest approximation needed to compute $\mathrm{m}_{\text {res }}$ according to Equation (13), is to assume that the temperature of the residuals $\left(\mathrm{T}_{\mathrm{res}}\right)$ is equal to the mean temperature measured at the exhaust manifold. However, particularly for this 2-stroke engine architecture with relatively high short-circuit losses, the temperature in the exhaust manifold is expected to be comparatively lower than the temperature of the residuals. So, $\mathrm{T}_{\text {res }}$ is estimated using Equation (14), derived from a complementary mass and energy balance at the exhaust manifold, taking into account the flow and the temperature at the exhaust $\left(\mathrm{T}_{\text {exh }}\right)$ measured before the EGR extraction point, and the short-circuited flow and temperature $\left(T_{\text {short }}\right)$ given by the mixture of intake fresh air and EGR.

$$
T_{\text {res }}=\frac{C_{\text {pexh }} \cdot\left(m_{\text {del }}+m_{\text {fuel }}\right) \cdot T_{\text {exh }}-C_{\text {phort }} \cdot m_{\text {short }} \cdot T_{\text {short }}}{C_{\text {pexh }} \cdot\left(m_{\text {del }}+m_{\text {fuel }}-m_{\text {short }}\right)}
$$

Considering that the 2-cylinder engine concept presents a double stage supercharging system, with a mechanical volumetric charger set downstream to a waste-gaste (WG) turbocharger, ${ }^{37,38}$ it is valuable to estimate the energetic cost required to achieve the intake conditions, to obtain an approximation of the expected or "equivalent" indicated specific fuel consumption (denoted as $\mathrm{ISFC}_{\text {corr }}$ ) which could be obtained on the two-cylinder engine. This correction is useful for estimating qualitatively the increase in BSFC expected at the engine with fully assembled air charging system, and to avoid conditions which are not feasible in the engine due to very highpressure ratios or extremely high air flow rates, which would imply a high penalty in BSFC because of the high power demanded by the supercharger. ISFC corr $_{\text {is }}$ calculated according to Equation (15) multiplying the ISFC measured in the single-cylinder engine with a factor that considers the effective power demanded by the supercharger $\left(\mathrm{P}_{\text {weff,sc }}\right)$ that would be taken from the indicated power $\left(\mathrm{P}_{\text {wind }}\right)$ delivered to the crankshaft. 


$$
I S F C_{\text {corr }}=I S F C \cdot \frac{P_{\text {wind }}}{P_{\text {wind }}+P_{\text {weff,sc }}}
$$

In order to provide a fast approximation of ISFC $_{\text {corr }}$ if all air loop devices were present, the effective power required by the supercharger is estimated by resolving simple mass and energy balances on the turbine, compressor and supercharger, considering the experimentally measured data (temperature, pressure and mass ow rates) as inputs for the calculation. The following assumptions were made to simplify the calculation:

- A constant value of $60 \%$ efficiency is assumed for all the air loop devices. This simplification is slightly optimistic especially for points with low-pressure ratios and low flow rates.

- Atmospheric pressure (1 bar absolute) is set at the inlet of the first compression stage, neglecting any pressure drop in the filter system.

- A pressure of (1:2 bar absolute) is set at the outlet of the turbine, assuming there are some pressure drops after the turbine from the other components of the exhaust system.

- The temperature at the inlet of the first compression stage is equal to the exhaust temperature experimentally measured in the exhaust manifold. This assumption considers that the turbine will be placed as close as possible to the engine.

In order to obtain good accuracy in the separation of the accumulation particle mode, PSDs can be decomposed by Equation (16) according to Seinfeld et al. ${ }^{47}$ It is established that the total PSD is the sum of both particle mode concentrations (nucleation-mode and accumulation-mode), assuming the log-normal size distribution function:

$$
\frac{d N_{i}}{d \log d p_{i}}=\frac{1-x}{\sqrt{2 \pi} \log \sigma_{g 1}} \cdot e^{-\frac{\log ^{2}\left(\frac{d p_{1}}{d p_{g 1}}\right)}{2 \log ^{2} \sigma_{g 1}}}+\frac{1-x}{\sqrt{2 \pi} \log \sigma_{g 2}} \cdot e^{-\frac{\log ^{2}\left(\frac{d p_{2}}{d p_{g}}\right)}{2 \log ^{2} \sigma_{g 2}}}
$$

Where $x$ is the ratio of the total concentrations number of two distributions, $\mathrm{d}_{\mathrm{p} 1}, \mathrm{~d}_{\mathrm{p} 2}, \mathrm{~d}_{\mathrm{pg} 1}, \mathrm{~d}_{\mathrm{pg} 2}, \sigma_{1}$ and $\sigma_{2}$ are the geometric mean diameters, median diameters, and geometric standard deviations of each peak, and $\mathrm{N}_{\mathrm{i}}$ is the particle concentration of particle size $\mathrm{d}_{\mathrm{pi}}$. The fit was achieved by minimizing the mean square error function by means of the Nelder-Mead simplex method.

Furthermore, to calculate the different particle-mode concentrations $\left(\mathrm{N}_{\text {mode }}\right)$, Equation (17) was used. In this equation, $\mathrm{dp}_{(\text {(up) }}$ and $\mathrm{dp}_{(\mathrm{down})}$ are the particle size limits defining the range of the diameters for each mode. The following decomposition was considered:

- Nucleation-mode $\left(\mathrm{N}_{\mathrm{Nuc}}\right)$ : particle sizes from $\mathrm{dp}_{(\text {down })}=6.3 \mathrm{~nm}$ to $\mathrm{dp}_{(\text {(up) }}=30 \mathrm{~nm}$.

- Accumulation-mode $\left(\mathrm{N}_{\text {Acc. }}\right)$ : particle sizes from $\mathrm{dp}_{(\mathrm{down})}=30 \mathrm{~nm}$ to $\mathrm{dp}_{(\mathrm{up})}=237 \mathrm{~nm}$.

- Finally, the total-mode $\left(\mathrm{N}_{\text {Tot. }}\right)$ particle concentration was considered from $\mathrm{dp}_{(\mathrm{down})}=6.3 \mathrm{~nm}$ to $\mathrm{dp}_{(\mathrm{up})}=237 \mathrm{~nm}$.

$$
N_{\text {mode }}=\sum_{d p(\text { low })}^{d p(\text { up })} d N_{i}
$$

Once each particle-mode concentration was calculated, Equation (18) was used to obtain the instantaneous particle emission for each mode. In this Equation, $\dot{\mathrm{m}}_{\mathrm{exh}}$ is considered as the instantaneous exhaust mass flow, while $\rho_{\text {exh }}$ is the exhaust gas density at the sample point.

$$
P E_{\text {mode }}[\# / \mathrm{s}]=N_{\text {mode }}\left[\# / \mathrm{m}^{3}\right] \cdot \frac{\dot{\mathrm{m}}_{\text {exh }}[\mathrm{kg} / \mathrm{s}]}{\rho_{\text {exh }}\left[\mathrm{kg} / \mathrm{m}^{3}\right]}
$$

Finally, to obtain the indicate specific particle number of each mode (ISPN ${ }_{\text {mode }}$ ), Equation (19) was employed. It was obtained as the relationship between $\mathrm{PE}_{\mathrm{mode}}$ and the indicate power $\left(\mathrm{P}_{\text {wind }}\right)$.

$$
I S P N[\# / k W i]=\frac{3600 \cdot P E_{\text {mode }}[\# / s]}{P_{\text {wind }}[k W i]}
$$

To calculate the geometric mean diameter (GMD) of the entire PSDs, Equation (20) was applied:

$$
G M D=\frac{\sum_{d p(l o w)}^{d p(u p)} d N_{i} \ln d p_{i}}{d N}
$$

The numerical concentration was converted into mass concentration (dM) following the Equation (21), which was experimentally determined using the particle density on a GDI engine. ${ }^{48}$

$$
d M_{i}=1.72 \cdot 10^{-24} \cdot d p_{i}{ }^{2.65}
$$


The mass to diameter relation was determined using the density, with a power law fit yielding a fractal dimension of 2.65. The fractal dimension gives an indication of the extent to which a particle appears to fill space; if the particles were spherical they would have a fractal dimension of 3.0. ${ }^{49}$

\subsection{Test schedule}

In this research work, a parametric study was carried out based on the independent modification of three air management parameters: $\Delta \mathrm{P}$, OLAP period and EGR rate, from a reference point, which corresponds to nominal engine configuration in each steady-state operation mode. The main characteristics of these operating points are shown in Table 3, where the reference point settings are indicated in bold. The operation modes are defined by their engine speed and IMEP and are denoted as A2000 (3.5 bar IMEP and $2000 \mathrm{rpm}$ ), B2000 (5.5 bar IMEP and $2000 \mathrm{rpm}$ ) and C2500 (5.5 bar IMEP and $2500 \mathrm{rpm}$ ).

Table 3. Experimental plan for the parametric study.

\begin{tabular}{|c|c|c|c|c|c|c|c|c|c|c|c|}
\hline Point & $\begin{array}{l}\text { Speed } \\
{[\text { rpm }]}\end{array}$ & $\begin{array}{l}\text { IMEP } \\
{[\mathrm{bar}]}\end{array}$ & $\begin{array}{l}\text { OLAP } \\
{[\mathrm{CA}]}\end{array}$ & $\begin{array}{l}\Delta \mathbf{P} \\
{[\mathrm{mbar}]}\end{array}$ & $\begin{array}{l}\text { EGR } \\
{[\%]}\end{array}$ & $\begin{array}{l}\mathbf{I P} \\
{[\mathrm{bar}]}\end{array}$ & $\begin{array}{l}\text { SoE1 } \\
\text { [CA aTDC] }\end{array}$ & $\begin{array}{l}\text { SoE2 } \\
\text { [CA aTDC] }\end{array}$ & $\begin{array}{l}\text { SoE3 } \\
\text { [CA aTDC] }\end{array}$ & $\begin{array}{l}\mathbf{M}_{\text {fuel }} \\
{[\mathrm{mg} / \mathrm{st}]}\end{array}$ & $\begin{array}{l}\text { \%Fuel } \\
{[\mathrm{SoE} 1 / 2 / 3]}\end{array}$ \\
\hline \multirow[t]{3}{*}{ A2000 } & 2000 & 3.5 & 62.4 & 210 & 23 & 400 & - & -42 & 10 & 7.4 & $-/ 76 / 24$ \\
\hline & & & 64.4 & 230 & 26 & & & & & & \\
\hline & & & 66.4 & 250 & 29 & & & & & & \\
\hline \multirow[t]{3}{*}{ B2000 } & 2000 & 5.5 & 61.4 & 450 & 31 & 600 & -60 & -42 & 10 & 11.5 & $18 / 62 / 20$ \\
\hline & & & 62.4 & 475 & 34 & & & & & & \\
\hline & & & 63.4 & 500 & 37 & & & & & & \\
\hline \multirow[t]{3}{*}{$\mathrm{C} 2500$} & 2500 & 5.5 & 63.4 & 450 & 25 & 600 & -60 & -44 & 10 & 11.8 & $18 / 65 / 17$ \\
\hline & & & 65.4 & 475 & 27 & & & & & & \\
\hline & & & 67.4 & 500 & 29 & & & & & & \\
\hline
\end{tabular}

A multiple injection strategy (triple or double injection) was used in all studies presented in this research, with a fixed fuel mass flow which provided the required IMEP target at each engine speed. The total fuel injected quantity, injection pressure (IP), 1sd injection, 2nd injection and 3rd injection timing were kept constant for each operation mode, as shown in Table 3, the injection timing corresponds to the start of energizing (SoE) of the injector. This procedure is very important to avoid the influence of these injection parameters on the cylinder conditions and consequently on combustion process and exhaust emissions, leaving only air management parameters variations as the responsible for the PM emissions variations.

In previous work and specifically in this engine, the effects of injection parameters on engine performance and exhaust emissions were analyzed. ${ }^{28,29}$ Therefore, with the aim of continuing to explore the PPC concept, the focus of this research is exclusively on the analysis of air management. Moreover, the main reason for selecting these operation modes is due to the possibility of evaluating the behavior of the particles in both structures of the size distribution. The particle size distributions of the A2000 operation mode were dominated by nucleation-mode. In the case of the B2000 operation mode, the PSDs were observed both in nucleation and accumulation-mode. And finally, for the $\mathrm{C} 2500$ operation mode, the size distributions were kept in the accumulation-mode and with high values.

Finally, in order to control all the aspects that could introduce variability in the measurements and to reduce the experimentation time as much as possible, the measurement methodology proposed in the work of Benajes et al. ${ }^{50}$ was adopted.

\section{Results and discussion}

In this context, in this section the experimental results of different air management strategies will be analyzed

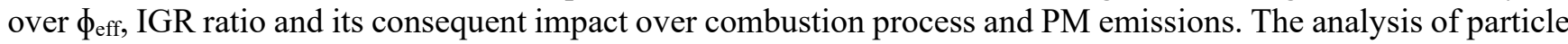
emissions will be carried out through their lognormal size distribution, including both numerical and mass concentrations. Additionally, the GMD values of the particle concentrations for each operation mode will also be evaluated.

\subsection{Influence of the differential pressure between intake and exhaust (AP)}

Figure 4 illustrates how the increase in $\Delta \mathrm{P}$ provides a decrease in $\phi_{\text {eff }}$ and IGR values, in the three operation modes. Increasing $\Delta \mathrm{P}$ results in higher delivered charge mass (fresh air $+\mathrm{EGR}$ ), and although the short-circuit losses are inevitably greater, the total mass trapped in the cylinder increases and, as the injected fuel quantity 
remains constant, the $\phi_{\text {eff }}$ decreases. Additionally, the reduction in IGR ratio confirms this improvement in the scavenging process that occurs when $\Delta \mathrm{P}$ increases.

Figure 4 also shows a higher IGR values that varied between $29.5 \%$ for $\mathrm{C} 2500$ operation mode and $42.2 \%$ for A2000 operation mode. This intrinsic characteristic of the 2-stroke architecture allows to for the increase of the initial gas temperature and its evolution during the compression stroke, assuring proper ignition of a higheroctane gasoline (RON95) in PPC conditions. The differences in the IGR ratios among operation modes are mainly due to the difference in load among them. As the load increases, there is a higher tendency towards knocking-like combustion that makes necessary to decrease IGR as much as possible.

[insert Figure 4.]

[insert Figure 5.]

In PPC concept and specifically in this type of 2-stroke poppet valves architecture the combustion process is highly sensitive to the $\phi_{\text {eff }}$ and IGR ratios. ${ }^{51}$ An increment of $\Delta \mathrm{P}$ worsens the air/fuel mixture reactivity, which results in longer ignition delays and a decrease in the maximum peak of the RoHR profile, as shown in Figure 5. This trend can be explained by a decrease in $\phi_{\text {eff }}$ stratification and IGR ratio, according to Figure 4.

Figures $6 \mathrm{~A}, 6 \mathrm{~B}, 6 \mathrm{C}, 6 \mathrm{~A} .1,6 \mathrm{~B} .1$ and $6 \mathrm{C} .1$ show the effect of $\Delta \mathrm{P}$ variation over the start of combustion (represented by CA10), CA50, the maximum pressure gradient $\left(\mathrm{dP} / \mathrm{d} \alpha_{\max }\right)$ and $\mathrm{P}_{\max }$, in the three operation modes. In general terms, as expected from the trends already observed in RoHR (Figure 5), the advance of CA10 and CA50 provide an increase in $\mathrm{dP} / \mathrm{d} \alpha_{\max }$ and $\mathrm{P}_{\max }$. As a result of the high $\mathrm{P}_{\max }$, the local temperature of the reaction zones increases enhancing the particles formation along the combustion process, as will be seen below.

\section{[insert Figure 6.]}

The increase in $\triangle \mathrm{P}$, also, increments the cycle-to-cycle dispersion in the cylinder pressure, which resulted in a rise in COV $\mathrm{P}_{\max }$, as is shown in Figures 4A.2, 4B.2 and 4C.2. However, the effect on the COV IMEP was lower and neither of the operation modes exceeded 3\%. As expected, the combustion phasing delay and the low temperatures provided a gradual loss of control over the combustion stability to a point where misfire cycles started to appear. This behavior was clearly observed in A2000 operation (Figure 5A) mode where tests with $\Delta \mathrm{P}$ higher than 250 mbar were not possible due to the high rate of misfiring cycles.

Before starting the analysis of $\mathrm{PM}$ emissions and, since the $\Delta \mathrm{P}$ variation has strong effects on combustion process, it would be interesting to take into account some important considerations regarding the soot particle formation process during the combustion process. As already mentioned in the Introduction section, the particle formation process includes phenomena such as nucleation, surface growth, and coagulation.

The nucleation process occurs under fuel-rich conditions and high combustion temperature. This phenomenon gives rise to a large number of primary soot particles with a diameter of less than $2 \mathrm{~nm}$ and with an insignificant soot load. ${ }^{52,53}$ In the final stage of soot formation, surface growth is a predominant process which occurs due to the addition of mass on the nucleate soot particle surface and leads to an increase in soot mass. ${ }^{14}$ Coagulation is another mechanism that occurs in this phase, which is characterized by the collision of the nuclei, fusing with each other, giving rise to aggregates in the form of a chain (secondary particles), with a consequent increase in size, the particle number present is reduced in this process. ${ }^{13,54}$ Unlike the phenomenon of surface growth, which occurs in a defined phase, the oxidation phenomenon takes place during all stages of soot formation. ${ }^{55,56}$

The effect of the nucleation-mode on particle mass distribution is insignificant due to the small particle size. In contrast, the very large particle size of the accumulation-mode makes this mode particularly noticeable with respect to the nucleation-mode when representing the particle mass distribution.

Returning to the analysis of the experimental results, the decrease in $\Delta \mathrm{P}$ causes a rise in mixture stratification in terms of $\phi_{\text {eff }}$ and in in-cylinder initial gas temperature, indicated by the high IGR ratio. The behavior of these two parameters turns an increasingly reactive charge and a shorter time for the air/fuel mixture preparation, shown by the advance of CA10 and CA50 (Figures 6A, 6B, and 6C). Additionally, both parameters cause higher combustion temperatures, shown by the increase in $\mathrm{dP} / \mathrm{d} \alpha_{\max }$ and $\mathrm{P}_{\max }$ values (Figures 6A.1, 6B.1 and 6C.1). Considering that the first step for particle formation occurs under local rich equivalence ratio zones and depends on the high temperatures, it is possible to confirm that the decrease in $\Delta \mathrm{P}$ facilitates the nuclei-precursor particle formation process, as shown in Figures 7A.1, 7B.1 and 7C.1, by the increment in total PN emissions in the three operation modes. For the A2000 operation mode the total particle concentration increased by up to $93 \%$ (from $5.96 \times 10^{13} \# / \mathrm{kWi}$ for $250 \mathrm{mbar}$ to $1.15 \times 10^{14} \mathrm{\#} / \mathrm{kWi}$ for $210 \mathrm{mbar}$ ); for the B2000 operation mode there was an 
increase of around $97 \%$ (from $1.24 \times 10^{14} \# / \mathrm{kWi}$ for $500 \mathrm{mbar}$ to $2.44 \times 10^{14} \# / \mathrm{kWi}$ for $450 \mathrm{~m}$ bar); and for the $\mathrm{C} 2500$ operation mode it was $59 \%$ (from $4.21 \times 10^{14} \# / \mathrm{kWi}$ for $500 \mathrm{mbar}$ to $6.13 \times 10^{14} \mathrm{\#} / \mathrm{kWi}$ for $450 \mathrm{mbar}$ ).

\section{[insert Figure 7.]}

In the three operation modes, it was observed how the PSDs shifted towards larger sizes with the $\triangle \mathrm{P}$ decreases, incrementing the particle concentration of the accumulation mode (Figures 7A, 7B, and 7C). With more nuclei particles, the surface growth and coagulation rates also increase.$^{57-59}$ As a result, when the $\Delta \mathrm{P}$ decreases, the number and size of the particles increases.

In 250 bar in the A2000 operation mode and in 500 bar in the B2000 operation mode the size distributions were dominated by the nucleation-mode (Figure 7A and 7B). Moreover, $\mathrm{HC}$ emissions were also higher at these operating points. For the A2000 operation mode, the $\mathrm{HC}$ emissions increased up to $40 \%$ (from $2.51 \mathrm{~g} / \mathrm{kWi}$ for 210 bar to $3.51 \mathrm{~g} / \mathrm{kWi}$ for $250 \mathrm{bar}$ ) for the B2000 operation mode this increase was $69 \%$ (from $1.89 \mathrm{~g} / \mathrm{kWi}$ for 450 bar to $3.21 \mathrm{~g} / \mathrm{kWi}$ for $500 \mathrm{bar}$ ), and for the $\mathrm{C} 2500$ operation mode $\mathrm{HC}$ emissions remained relatively constant around $1.68 \mathrm{~g} / \mathrm{kWi}$. This trend may be associated with the low amount of carbonaceous particle generated at these operating points. In these cases, the nucleation-mode is promoted against the accumulation-mode due to the low absorption of volatiles that can take place on the surface of the soot particle under these conditions. ${ }^{60,61}$

To better understand how the combustion process affects the particles formation process and their evolution in the combustion chamber, Figure 8 shows the GMDs variation according to two key parameters of the combustion process: $P_{\max }$ and CA50. The GMD values point out the overall value of PSD, considering both particle emission for each diameter and total particle emission (Equation 18). In the three operation modes, it was observed how the faster mixing time process (represented by the CA50 advance, once the injection timing remains constant) and the higher combustion temperature (represented by the rise in $\mathrm{P}_{\max }$ ) increase the GMDs, indicating that the processes of surface growth and coagulation are advantaged under these conditions.

\section{[insert Figure 8.]}

[insert Figure 9.]

Although the aim of this work is not to evaluate the use of different air management strategies in terms of engine performance, the analysis of the behavior of ISFC and ISFC corr for each operation point is important to identify whether the air management parameters variations are really viable in each operation mode. As shown in Figure 9, a slight increase in ISFC and ISFC $_{\text {corr }}$ was observed with the $\triangle \mathrm{P}$ increment for the three operation modes. The results can be explained by longer ignition delays as shown in Figures $6 \mathrm{~A}, 6 \mathrm{~B}$, and $6 \mathrm{C}$ with the delay of CA10 and CA50. Due to the later combustion phase, the effective expansion ratio of the engine is reduced and then leads the ISFC to increase. ${ }^{62}$ However, the effect of $\Delta \mathrm{P}$ variations on these parameters is low (less than $4 \%$ ).

\subsection{Influence of the valve overlap (OLAP) period.}

The effect of the OLAP period can be considered as complementary to those of the $\Delta \mathrm{P}$. With the increase in OLAP period the scavenging process improves, the fresh air trapped mass is higher, and the burnt gas fraction is lower, as shown in Figure 10 with the decrease in $\phi_{\text {eff }}$ and IGR values.

[insert Figure 10.]

[insert Figure 11.]

The straight effect of lowering trapped charge reactivity when increasing in-cylinder density (higher oxygen concentration) by the increasing OLAP period consists in a delay of the combustion phasing with softened and wider rate of heat release, lower maximum cylinder pressure, and pressure gradient, as confirmed by RoHR profiles in Figure 11 and $\mathrm{P}_{\max }, \mathrm{dP} / \mathrm{d} \alpha_{\max }$ in Figures 12A.1, 12B.1 an 12C.1 for the three operation modes.

\section{[insert Figure 12.]}

Concerning PN emissions, Figures 13A.1, 13B.1 and 13C.1 shows how the reduction in valve overlap period increases the particle emissions in the three operation modes. This is mainly related to a decrease in the ignition delay and consequently in the time available to evaporate and mix the fuel injected (as illustrated in Figures 12A.1, 
12B.1, and 12C.1 with the advance in CA10 and CA50 values). In these conditions, the locally fuel-rich zones extend considerably favoring the particles formation process.

[insert Figure 13.]

Figures 13A, 13B and 13C show how the PSDs shift substantially towards larger sizes with OLAP period decreases. This trend may be linked to a considerable favoring of surface growth and coagulation rate provided by the significant increase in particle precursors (nuclei particles), which are formed when the partially premixed flame propagates through these locally fuel-rich zones. Additionally, in the A2000 and B2000 operation modes, it is clearly observed how the increase of the accumulation-mode particles decreases the nucleation-mode particles concentration, confirming that the soot particles increase their size through the absorption of volatile condensates, similar results were obtained in the works of Pei et al..$^{63}$ and Singh et al. ${ }^{64}$

As in some operation points of the $\Delta \mathrm{P}$ variation, in the operating points $66.4 \mathrm{CA}$ and $67.4 \mathrm{CA}$ in $\mathrm{A} 2000$ and B2000 operation mode, respectively there were high nucleation-mode particles concentrations and additionally was observed high $\mathrm{HC}$ emissions values $(3.52 \mathrm{~g} / \mathrm{kWi}$ for $66.4 \mathrm{CA}$ in the A2000 operation mode and $2.87 \mathrm{~g} / \mathrm{kWi}$ for 63.4 CA in the B2000 operation mode). This trend confirms the hypothesis that the particles formation is closely related to unburned hydrocarbons. ${ }^{10}$

The close link between the time for the air/fuel mixture preparation and the particle formation process can be observed when comparing Figure 12 with Figure 13. For example, in the operation mode B2000 in Figure 12B it is possible to observe how varying the OLAP period from 61.4 to 62.4 provides a slight increase in CA10 and CA50, which led to accumulation-mode particle decreases of $18.2 \%$ (from $2.31 \times 10^{14} \mathrm{\#} / \mathrm{kWi}$ to $1.89 \times 10^{14} \mathrm{\#} / \mathrm{kWi}$ ). The same correlation was also obtained when modifying the OLAP period from 62.4 to 63.4 , however, in this case a higher increase in CA10 and CA50 was observed and consequently a decrease in accumulation-mode particles of $67 \%$ (from $6.24 \times 10^{13} \# / \mathrm{kWi}$ to $1.89 \times 10^{14} \mathrm{\#} / \mathrm{kWi}$ ). Figure 14 shows a similar trend, but in relation to the GMD values. In the three operating modes it was observed that the ignition delay (through the CA50) and the combustion temperatures (represented by the $\mathrm{P}_{\max }$ ) have a great impact on the particles size. The GMDs decrease almost commensurate to the delay of CA50 and the decrease in $\mathrm{P}_{\max }$.

[insert Figure 14.]

[insert Figure 15.]

Finally, as shown in Figure 15, as with the $\triangle \mathrm{P}$ and OLAP period variation in the ranges studied does not

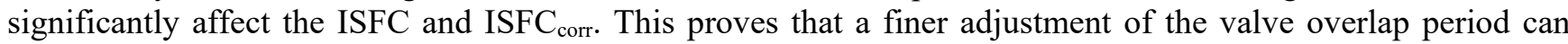
reduce $\mathrm{PN}$ emissions considerably without affecting engine efficiency.

\subsection{Influence of the EGR rate.}

In the PPC concept, to lower the combustion temperature and to decrease the NOx thermal formation mechanisms it is necessary to use high EGR rates. ${ }^{28}$ However, high EGR percentage has a significant impact on combustion stability, which can be reduced by readjusting the $\Delta \mathrm{P}$ and/or OLAP period to increase trapping and IGR ratios. This ensures adequate ignition of a less reactive cylinder charge. In this way, no significant changes were made in the EGR rates, considering that the main objective of this work is to perform a parametric study of each air management parameter while all other parameters remain constant.

As expected, in Figure 16 it is shown how the reduction of the oxygen concentration caused by an increase in the EGR rates affects the stratification of the mixture, slightly increasing the $\phi_{\text {eff }}$ while the IGR remains relatively constant in the three operation modes. Previously it was detected that the increase in the mixture stratification in terms of $\phi_{\text {eff }}$ and in the IGR ratio caused by lower OLAP period and $\triangle \mathrm{P}$ provides an increasingly reactive load that upsets the combustion process. However, the slight increase in the mixture stratification provided by the higher EGR rates does not influence the combustion process; in this case, the less reactive total trapped mass is responsible for the combustion phase delay and a lower rate of heat release and cylinder pressure, as confirmed in Figure 17 with the RoHR profile and Pcyl. 
Figures 18A, 18B, 18C, 18A.1, 18B.1 and 18C.1 show with more detail the trend in Figure 17. The increase in EGR rate delays the CA10 and CA50 while it reduces the $\mathrm{P}_{\max }$ and $\mathrm{dP} / \mathrm{d} \alpha_{\max }$ in the three operation modes. It is important to note that these variations were generally lower than those provided by the $\triangle \mathrm{P}$ and OLAP period, a trend that may be related to the reduced variation of the EGR rate (only 3 percent between the measurement points). The reduced variation of COV IMEP and COV $\mathrm{P}_{\max }$ in Figures 18A.2, 18B.2, and 18C.2, confirm the lower impact of the EGR rates over combustion process.

[insert Figure 18.]

Regarding PM emissions, Figures 19A.1, 19B.1 and 19C.1 show an increase in particle emissions with the decrease in EGR rate in the B2000 and C2500 operation modes and in accumulation-mode of the A2000 operation mode, being similar results as reported by Bermúdez et al. ${ }^{65}$ This variation was lower than in the previously analyzed two parameters ( $\triangle \mathrm{P}$ and OLAP period), a behavior that is mainly due to the reduced impact of the EGR rate variation on the ignition delay and therefore on the time available for the air/fuel mixture preparation. Figures 19A, 19B and 19C show how the PSDs do not significantly shift with the decrease in the EGR rate in any of the three operation modes, which means that the slight increase in the number of primary particles provided by the variation of this event is not enough to promote significant particle growth. This trend can also be observed in the reduced variation of the GMDs, in Figure 20.

[insert Figure 19.]

The small variations of the PN emissions for the different EGR rates in each operation mode allow for the comparison of the particle emissions between the operation modes. In this case, the load and engine speed would be responsible for the changes in PM emissions values.

It is possible to observe how PSDs are in the nucleation-mode for the operation mode A2000 (3.5 bar of IMEP). Moreover, the $\mathrm{HC}$ emissions were also higher than in the other operation modes, this increase was approximately $120 \%$ (of 1.60 and $1.71 \mathrm{~g} / \mathrm{kWhi}$ for the operation modes B2000 and C2500 respectively to 3.52 $\mathrm{g} / \mathrm{kwhi}$ for the operation mode A2000). Therefore, probably this high concentration of nucleation-mode particles is related to the condensation and coagulation of unburned hydrocarbons, due to a lower combustion temperature that occurs under these conditions. ${ }^{59}$ This comparatively lower combustion temperature achieved in A2000 operation mode can be confirmed in Figures 16A.1, 16B.1 an 16C.1 with the lower $\mathrm{dP} / \mathrm{d} \alpha_{\max }$ and $\mathrm{P}_{\max }$ values compared to the $\mathrm{B} 2000$ and $\mathrm{C} 2500$ operation modes

When switching from A2000 to B2000 operation mode, the PSDs shifted to accumulation-mode (Figure 17A and 17B). Specifically, when comparing both reference points, the increase in PN emissions was $181 \%$ (from $6.44 \times 10^{13} \mathrm{\#} / \mathrm{kWi}$ to $1.81 \times 10^{14} \mathrm{\#} / \mathrm{kWi}$ ), a result that can be associated with the increase in the fuel mass (from 7.3 $\mathrm{mg} / \mathrm{st}$ for A2000 operation mode to $11.5 \mathrm{mg} / \mathrm{st}$ for B2000 operation mode), which leads to a less efficient process in the air/fuel mixture preparation and an increase in the combustion temperature. ${ }^{66,67}$ Both factors favor the carbonaceous particles formation and NOx emissions.

The thermal NOx formation is produced by the reaction between nitrogen and oxygen during the combustion process at high temperatures. This reaction takes place above $1300 \mathrm{~K}$ in locally richer zones and increases exponentially with temperature increase ${ }^{68}$ Therefore, contrary to the behavior of $\mathrm{HC}$ emissions, that were favored by the reduction of the combustion temperature, the NOx emissions increased with the increases of the engine load, which in this case was from $3.5 \mathrm{bar}$ (A2000 operation mode) at $5.5 \mathrm{bar}$ (B2000 operation mode). The increase was up to $192 \%$ (from $0.25 \mathrm{~g} / \mathrm{kWhi}$ for A2000 to $0.73 \mathrm{~g} / \mathrm{kWhi}$ for B2000).

Additionally, a shift of the PSDs from B2000 to larger sizes (mode of operation C2500) was observed, with a considerable increase in particles emission, which was of $206 \%$ (from $1.81 \times 10^{14} \mathrm{\#} / \mathrm{kWi}$ for the B2000 reference point to $5.54 \times 10^{14} \# / \mathrm{kWi}$ for the $\mathrm{C} 2500$ reference point). In this case, although there are no significant variations in the fuel mass, the increase of the engine speed (2000 rpm to $2500 \mathrm{rpm})$ provides a shorter time for air/fuel mixture preparation and for the particles oxidation, resulting in an increase in PN emissions as shown in Figure 17B.1 and 17C.1. However, between the B2000 and C2500 operation modes, no significant variations were observed in $\mathrm{HC}$ and NOx emissions. Trend that may be related to the reduced variation of the $\mathrm{P}_{\max }$ values and consequently of the combustion temperature between both operation modes. 
Finally, Figure 21 shows how the EGR rate variation does not influence over the ISFC and ISFC corr, in any of the three operation modes. Additionally, Figure 21 illustrates how increasing the engine load, or what is the same, switch from A2000 to B2000 and C2500 operation mode respectively, causes an increase in $\mathrm{ISFC}_{\text {corr }}$ despite the reduced variation of ISFC. In this case, the additional air mass flow that is required when increasing the engine load provides an increase in the power demanded by the air management devices, especially by the mechanical supercharger, with a significant penalty in the $\mathrm{ISFC}_{\text {corr }}$ final. ${ }^{29,51}$

\section{Conclusions}

This paper presented a research work carried out in a two-cylinder 2-stroke HSDI CI engine operating with PPC concept and fueled with conventional RON 95 gasoline. The effects of three air management parameters: $\Delta \mathrm{P}$,

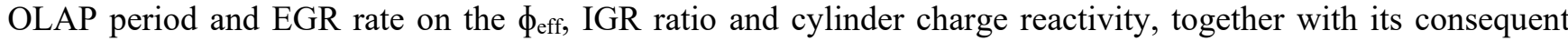
impact on PN emissions, particle size distribution and GMDs were experimentally investigated in three steadystate operation modes.

The knowledge acquired in these experiments are indispensable to fully map the engine for real condition applications. The results can by directly implemented during the engine calibration due to a finer adjustment of the air management parameters allows for the reduction of the PM emissions without significant alterations in engine efficiency.

The increase in $\triangle \mathrm{P}$ and OLAP period decreases the $\phi_{\text {eff }}$ stratification and IGR ratio, affecting the global mixture reactivity and delaying the combustion phasing. This increases the time available for the air/fuel mixture preparation, decreasing the fuel-rich zones and combustion temperatures. Under these conditions, the particle formation process is limited, which leads to a considerable decrease in PM emissions and in GMDs.

Additionally, the decrease in $\triangle \mathrm{P}$ and OLAP period provided a progressive shifting of the numeric and mass distribution towards larger sizes, increasing the particle concentration of the accumulation-mode and decreasing the particle concentration of nucleation-mode. This trend could be related to an increase in the absorption of volatiles that takes place on the surface of the carbonaceous particle.

The EGR rate variation had a reduced impact on mixture stratification in terms of $\phi_{\text {eff }}$ and in the IGR ratio, however, an increase in PM emissions was observed with the reduction of their values. In this case, the less reactive total trapped charge could be responsible for this behavior. Additionally, no significant shift was observed in the particle size distributions with the decrease in the EGR rate in any of the three operation modes, which means that the slight increase in the number of primary particles provided by the variation of this event is not enough to significantly promote the phenomena of surface growth and coagulation.

It was also observed that the engine speed and load conditions greatly influenced the particle size distribution and particle emissions. On the one hand, as the load increased, the PN emissions increased and a progressive shift of size distribution towards larger sizes was observed, behavior that could be associated with the increase in the fuel mass that occurs in these conditions. On the other hand, the reduction of the time available for air/fuel mixture preparation due to the increase of the engine speed provides an even more evident shift in the PSDs and an increase in particle emissions. Additionally, no significant decline in engine efficiency (ISFC and ISFC corr) was observed with the variations of the three air management parameters studied. However, the increase in engine load did affect the ISFC $_{\text {corr }}$, due to the power demanded by the supercharger to provide the required intake pressure.

Finally, it is important to consider that for particles smaller than $50 \mathrm{~nm}$, no significant values were observed in particles mass distribution, however, in some of these points, the particles numerical concentrations were significantly important. Therefore, the development of new methods and technologies to reduce these small particles should be a priority for vehicle manufacturers, mainly due to the significant evolution of PM emissions regulations in recent years. In this sense, although the European particle measurement program (PMP) method defines that only solid particles above a $23 \mathrm{~nm}$ threshold shall be measured, it will be almost impossible to rule out the possibility of measure particles with diameters below $23 \mathrm{~nm}$ in future legislation.

This study demonstrates how an appropriate air management strategy operating with the new PPC concept is not only important for proper engine performance tuning but also has a substantial impact on PM emissions. This is a very important aspect nowadays due to the new and demanding emission regulations.

\section{Acknowledgments}

The authors would like to thank RENAULT SAS for all the technical support provided to perform the research activities.

\section{Declaration of conflicting interests}


The authors declare that there is no conflict of interest.

\section{References}

1. Momenimovahed A, Olfert JS. Effective Density and Volatility of Particles Emitted from Gasoline Direct Injection Vehicles and Implications for Particle Mass Measurement. Aerosol Sci Technol 2015; 49: 1051-1062.

2. Robert MA, VanBergen S, Kleeman MJ, et al. Size and Composition Distributions of Particulate Matter Emissions: Part 1-Light-Duty Gasoline Vehicles. J Air Waste Manage Assoc 2007; 57: 1414-1428.

3. Kim K-H, Kabir E, Kabir S. A review on the human health impact of airborne particulate matter. Environ Int 2015; 74: 136-143.

4. McCreanor J, Cullinan P, Nieuwenhuijsen MJ, et al. Respiratory Effects of Exposure to Diesel Traffic in Persons with Asthma. N Engl J Med 2007; 357: 2348-2358.

5. Davidson CI, Phalen RF, Solomon PA. Airborne Particulate Matter and Human Health: A Review. Aerosol Sci Technol 2005; 39: 737-749.

6. Oberdörster G, Oberdörster E, Oberdörster J. Nanotoxicology: an emerging discipline evolving from studies of ultrafine particles. Environ Health Perspect 2005; 113: 823-39.

7. Lapuerta M, Armas O, Gómez A. Diesel Particle Size Distribution Estimation from Digital Image Analysis. Aerosol Sci Technol 2003; 37: 369-381.

8. Zhang Y, Ghandhi J, Rothamer D. Comparisons of particle size distribution from conventional and advanced compression ignition combustion strategies. Int J Engine Res 2017; 1-19.

9. Myung CL, Ko A, Park S. Review on characterization of nano-particle emissions and PM morphology from internal combustion engines: Part 1. Int J Automot Technol 2014; 15: 203-218.

10. Dickau M, Olfert J, Stettler MEJ, et al. Methodology for quantifying the volatile mixing state of an aerosol. Aerosol Sci Technol 2016; 50: 759-772.

11. Wang B, Mosbach S, Schmutzhard S, et al. Modelling soot formation from wall films in a gasoline direct injection engine using a detailed population balance model. Appl Energy 2016; 163: 154-166.

12. Leach F, Stone R, Richardson D, et al. Particulate emissions from a highly boosted gasoline direct injection engine. Int J Engine Res 2018; 19: 347-359.

13. Mueller ME, Blanquart G, Pitsch H. Hybrid Method of Moments for modeling soot formation and growth. Combust Flame 2009; 156: 1143-1155.

14. Mosbach S, Celnik MS, Raj A, et al. Towards a detailed soot model for internal combustion engines. Combust Flame 2009; 156: 1156-1165.

15. Giechaskiel B, Vanhanen J, Väkevä M, et al. Investigation of vehicle exhaust sub-23 nm particle emissions. Aerosol Sci Technol 2017; 51: 626-641.

16. Baumgard KJ, Johnson JH. The Effect of Fuel and Engine Design on Diesel Exhaust Particle Size Distributions. In: SAE Technical Paper, 960131. 1996.

17. Dec JE, Espey C. Ignition and Early Soot Formation in a DI Diesel Engine Using Multiple 2-D Imaging Diagnostics. In: SAE Technical Paper, 950456. 1995.

18. Schreiber D, Forss A-M, Mohr M, et al. Particle Characterisation of Modern CNG, Gasoline and Diesel Passenger Cars. In: SAE Technical Paper, 2007-24-0123. 2007.

19. Mathis U, Mohr M, Forss A-M. Comprehensive particle characterization of modern gasoline and diesel passenger cars at low ambient temperatures. Atmos Environ 2005; 39: 107-117.

20. Ganesh D, Nagarajan G. Homogeneous charge compression ignition (HCCI) combustion of diesel fuel with external mixture formation. Energy 2010; 35: 148-157.

21. Azimov UB, Kim KS, Jeong DS, et al. Evaluation of low-temperature diesel combustion regimes with n-Heptane fuel in a constant-volume chamber. Int J Automot Technol 2009; 10: 265-276.

22. Misztal J, Xu HM, Wyszynski ML, et al. Effect of injection timing on gasoline homogeneous charge compression ignition particulate emissions. Int J Engine Res 2009; 10: 419-430.

23. Alkidas AC. Combustion advancements in gasoline engines. Energy Convers Manag 2007; 48: 2751-2761.

24. Yao M, Zheng Z, Liu H. Progress and recent trends in homogeneous charge compression ignition (HCCI) engines. Prog Energy Combust Sci 2009; 35: 398-437.

25. Peng Z, Zhao H, Ma T, et al. CHARACTERISTICS OF HOMOGENEOUS CHARGE COMPRESSION 
IGNITION (HCCI) COMBUSTION AND EMISSIONS OF n-HEPTANE. Combust Sci Technol 2005; 177: $2113-$ 2150.

26. Cinar C, Uyumaz A, Solmaz H, et al. Effects of valve lift on the combustion and emissions of a HCCI gasoline engine. Energy Convers Manag 2015; 94: 159-168.

27. Qiu L, Cheng X, Liu B, et al. Partially premixed combustion based on different injection strategies in a light-duty diesel engine. Energy 2016; 96: 155-165.

28. Benajes J, Novella R, De Lima D, et al. Impact of injection settings operating with the gasoline Partially Premixed Combustion concept in a 2-stroke HSDI compression ignition engine. Appl Energy 2017; 193: 515-530.

29. Benajes J, Martín J, Novella R, et al. Understanding the performance of the multiple injection gasoline partially premixed combustion concept implemented in a 2-Stroke high speed direct injection compression ignition engine. Appl Energy 2016; 161: 465-475.

30. Ickes AM, Bohac S V, Assanis DN. Effect of fuel cetane number on a premixed diesel combustion mode. Int J Engine Res 2009; 10: 251-263.

31. Bunting BG, Wildman CB, Szybist JP, et al. Fuel chemistry and cetane effects on diesel homogeneous charge compression ignition performance, combustion, and emissions. Int J Engine Res 2007; 8: 15-27.

32. Manente V, Johansson B, Tunestal P, et al. Effects of Different Type of Gasoline Fuels on Heavy Duty Partially Premixed Combustion. SAE Int J Engines 2009; 2: 2009-01-2668.

33. Bedoya ID, Saxena S, Cadavid FJ, et al. Experimental study of biogas combustion in an HCCI engine for power generation with high indicated efficiency and ultra-low NOx emissions. Energy Convers Manag 2012; 53: $154-162$.

34. Hildingsson L, Kalghatgi G, Tait N, et al. Fuel Octane Effects in the Partially Premixed Combustion Regime in Compression Ignition Engines. In: SAE Technical Paper, 2009-01-2648. 2009.

35. Weall A, Collings N. Gasoline Fuelled Partially Premixed Compression Ignition in a Light Duty Multi Cylinder Engine: A Study of Low Load and Low Speed Operation. SAE Int J Engines 2009; 2: 2009-01-1791.

36. Solaka H, Aronsson U, Tuner M, et al. Investigation of Partially Premixed Combustion Characteristics in Low Load Range with Regards to Fuel Octane Number in a Light-Duty Diesel Engine. In: SAE Technical Paper, 2012-010684. 2012.

37. Tribotte P, Ravet F, Dugue V, et al. Two Strokes Diesel Engine - Promising Solution to Reduce CO2 Emissions. Procedia - Soc Behav Sci 2012; 48: 2295-2314.

38. Pohorelsky L, Brynych P, Macek J, et al. Air System Conception for a Downsized Two-Stroke Diesel Engine. In: SAE Technical Paper, 2012-01-0831. 2012.

39. Fierz M, Burtscher H. Separation of solid and volatile fraction by thermodesorption and hot dilution. In: 7th ETH Conference on Combustion Generated Nanoparticles. At Zurich, 2003.

40. Kasper M. The Number Concentration of Non-Volatile Particles - Design Study for an Instrument According to the PMP Recommendations. In: SAE Technical Paper, 2004-01-0960. 2004.

41. Desantes JM, Bermúdez V, Pastor J V, et al. Methodology for measuring exhaust aerosol size distributions from heavy duty diesel engines by means of a scanning mobility particle sizer. Meas Sci Technol 2004; 15: $2083-2098$.

42. Desantes JM, Bermúdez V, Molina S, et al. Methodology for measuring exhaust aerosol size distributions using an engine test under transient operating conditions. Meas Sci Technol 2011; 22: 115101.

43. Lapuerta M, Armas O, Hernandez JJ. Diagnosis of DI Diesel combustion from in-cylinder pressure signal by estimation of mean thermodynamic properties of the gas. Appl Therm Eng 1999; 19: 513-529.

44. Payri F, Molina S, Martín J, et al. Influence of measurement errors and estimated parameters on combustion diagnosis. Appl Therm Eng 2006; 26: 226-236.

45. Olsen DB, Hutcherson GC, Willson BD, et al. Development of the Tracer Gas Method for Large Bore Natural Gas Engines-Part II: Measurement of Scavenging Parameters. J Eng Gas Turbines Power 2002; 124: 686.

46. Olsen DB, Hutcherson GC, Willson BD, et al. Development of the Tracer Gas Method for Large Bore Natural Gas Engines-Part I: Method Validation. J Eng Gas Turbines Power 2002; 124: 678.

47. Seinfeld JH, Pandis SN. Atmospheric chemistry and physics : from air pollution to climate change. 2 nd ed. Hoboken, New Jersey: John Wiley \& Sons, 2006.

48. Symonds JPR, Price P, Williams PI, et al. Density of particles emitted from a gasoline direct injection engine. In: 12th ETH Conference on Combustion Generated Nanoparticles. At Zurich, 2008.

49. Chen L, Stone R, Richardson D. A study of mixture preparation and PM emissions using a direct injection engine fuelled with stoichiometric gasoline/ethanol blends. Fuel 2012; 96: 120-130.

50. Benajes JV, López JJ, Novella R, et al. ADVANCED METHODOLOGY FOR IMPROVING TESTING EFFICIENCY IN A SINGLE-CYLINDER RESEARCH DIESEL ENGINE. Exp Tech 2008; 32: 41-47.

51. Benajes J, Novella R, De Lima D, et al. Analysis of combustion concepts in a newly designed two-stroke high- 
speed direct injection compression ignition engine. Int J Engine Res 2015; 16: 52-67.

52. Bonatesta F, Chiappetta E, La Rocca A. Part-load particulate matter from a GDI engine and the connection with combustion characteristics. Appl Energy 2014; 124: 366-376.

53. Wang H. Formation of nascent soot and other condensed-phase materials in flames. Proc Combust Inst 2011; 33: 41-67.

54. Paul B, Datta A. Emission of hydrophilic soot precursor particulates from small gasoline engine at different load conditions. J Energy Inst 2013; 86: 78-84.

55. Stanmore B., Brilhac J., Gilot P. The oxidation of soot: a review of experiments, mechanisms and models. Carbon $N$ Y 2001; 39: 2247-2268.

56. Velji A, Yeom K, Wagner U, et al. Investigations of the Formation and Oxidation of Soot Inside a Direct Injection Spark Ignition Engine Using Advanced Laser-Techniques. In: SAE Technical Paper. 2010-01-0352. 2010.

57. Maricq MM, Podsiadlik DH, Brehob DD, et al. Particulate Emissions from a Direct-Injection Spark-Ignition (DISI) Engine. In: SAE Technical Paper, 1999-01-1530. 1999.

58. Sgro LA, Sementa P, Vaglieco BM, et al. Investigating the origin of nuclei particles in GDI engine exhausts. Combust Flame 2012; 159: 1687-1692.

59. Saxena MR, Maurya RK. Effect of premixing ratio, injection timing and compression ratio on nano particle emissions from dual fuel non-road compression ignition engine fueled with gasoline/methanol (port injection) and diesel (direct injection). Fuel 2017; 203: 894-914.

60. Kittelson DB, Watts WF, Johnson JP. On-road and laboratory evaluation of combustion aerosols Part1: Summary of diesel engine results. $J$ Aerosol Sci 2006; 37: 913-930.

61. Desantes JM, Bermúdez V, García JM, et al. Effects of current engine strategies on the exhaust aerosol particle size distribution from a Heavy-Duty Diesel Engine. J Aerosol Sci 2005; 36: 1251-1276.

62. Yuan Z, Liu J, Fu J, et al. Quantitative analysis on the thermodynamics processes of gasoline engine and correction of the control equations for heat-work conversion efficiency. Energy Convers Manag 2017; 132: 388-399.

63. Pei Y-Q, Qin J, Pan S-Z. Experimental study on the particulate matter emission characteristics for a direct-injection gasoline engine. Proc Inst Mech Eng Part D J Automob Eng 2014; 228: 604-616.

64. Singh AP, Agarwal AK. Experimental evaluation of sensitivity of low-temperature combustion to intake charge temperature and fuel properties. Int J Engine Res 2017; 146808741773021.

65. Bermúdez V, Luján JM, Climent H, et al. Assessment of pollutants emission and aftertreatment efficiency in a GTDi engine including cooled LP-EGR system under different steady-state operating conditions. Appl Energy 2015; 158: 459-473.

66. Kalghatgi GT, Risberg P, Angstrom H-E. Partially Pre-Mixed Auto-Ignition of Gasoline to Attain Low Smoke and Low NOx at High Load in a Compression Ignition Engine and Comparison with a Diesel Fuel. In: SAE Technical Paper. 2007-01-0006. 2007.

67. Arsie I, Di Iorio S, Vaccaro S. Experimental investigation of the effects of AFR, spark advance and EGR on nanoparticle emissions in a PFI SI engine. J Aerosol Sci 2013; 64: 1-10.

68. Hoekman SK, Robbins C. Review of the effects of biodiesel on NOx emissions. Fuel Process Technol 2012; 96: 237-249.

\section{Definitions/Abbreviations}

$\begin{array}{ll}\phi_{\text {eff }} & \text { effective equivalence ratio } \\ \Delta \mathrm{P} & \text { differential pressure between intake and exhaust } \\ \text { aTDC } & \text { after top dead center } \\ \mathrm{CA} & \text { crank angle } \\ \mathrm{CA} 10 & \text { crank angle for } 10 \% \text { of fuel burnt } \\ \text { CA50 } & \text { crank angle for } 50 \% \text { of fuel burnt } \\ \mathrm{CDC} & \text { Conventional Diesel Combustion } \\ \mathrm{CI} & \text { compression-ignition } \\ \mathrm{COV} & \text { coefficient of variation } \\ \mathrm{dN} & \text { number concentration } \\ \mathrm{dM} & \text { mass concentration } \\ \mathrm{dP} / \mathrm{d} \alpha_{\max } & \text { pressure gradient } \\ \text { EGR } & \text { exhaust gas recirculation }\end{array}$




$\begin{array}{ll}\text { ECU } & \text { engine control unit } \\ \text { HCCI } & \text { Homogeneous Charge Compression Ignition } \\ \text { ICE } & \text { internal combustion engines } \\ \text { IGR } & \text { internal gas recirculation } \\ \text { IMEP } & \text { indicated mean effective pressure } \\ \text { IP } & \text { injection pressure } \\ \text { ISPN } & \text { indicate specific particle number } \\ \text { ISFC } & \text { indicated specific fuel consumption } \\ \text { IVC } & \text { intake valve closing } \\ \text { NOx } & \text { nitrogen oxides } \\ \text { OLAP } & \text { valve overlap } \\ \text { PPC } & \text { Partially Premixed Combustion } \\ \text { PM } & \text { particulate matter } \\ \text { Pmax } & \text { peak cylinder pressure } \\ \text { PN } & \text { particle number } \\ \text { PSD } & \text { particle size distribution } \\ \text { RON } & \text { research octane number } \\ \text { RoHR } & \text { rate of heat release } \\ \text { SoE } & \text { start of energizing } \\ \text { SIDI } & \text { spark ignition direct injection } \\ \text { TR } & \text { trapping ratio } \\ & \end{array}$

\section{Figure Captions}

Figure 1. Sketch of the cylinder head designed for the 2-stroke engine architecture (Patent Renault FR2931880)

Figure 2. Lift profiles for intake and exhaust valves.

Figure 3. Experimental set-up for the evaluation of PN emissions and PSD in steady-state operating conditions.

Figure 4. Effect of $\Delta \mathrm{P}$ over the IGR ratio and $\phi_{\text {eff }}$ at each operation mode.

Figure 5. Effect of $\Delta \mathrm{P}$ over the cylinder pressure and RoHR at each operation mode.

Figure 6. Effect of $\Delta \mathrm{P}$ over combustion phase (CA10 and CA50), dP/d $\alpha_{\max }, \mathrm{P}_{\max }, \mathrm{COV} \mathrm{P}_{\max }$ and COV IMEP at each operation mode.

Figure 7. Effect of $\Delta \mathrm{P}$ over particle size distributions (PSD) and PN emissions at each operation mode.

Figure 8. Effect of combustion phase (CA50) and $\mathrm{P}_{\max }$ over the GMDs at each operation mode, during the $\Delta \mathrm{P}$ variations.

Figure 9. Effect of $\triangle \mathrm{P}$ over ISFC and $\mathrm{ISFC}_{\text {corr }}$ at each operation mode.

Figure 10. Effect of OLAP period over the IGR ratio and $\phi_{\text {eff }}$ at each operation mode.

Figure 11. Effect of OLAP period over the cylinder pressure and RoHR at each operation mode.

Figure 12. Effect of OLAP period over combustion phase (CA10 and CA50), dP/d $\alpha_{\max }, \mathrm{Pmax}, \mathrm{CoV} \mathrm{P}_{\max }$ and COV IMEP at each operation mode.

Figure 13. Effect of OLAP period over particle size distributions (PSD) and PN emissions at each operation mode.

Figure 14. Effect of combustion phase (CA50) and Pmax over the GMDs at each operation mode, during the OLAP period variations.

Figure 15. Effect of OLAP period over ISFC and ISFC $_{\text {corr }}$ at each operation mode.

Figure 16. Effect of EGR rate over the IGR ratio and air/fuel effective equivalence ratio ( $\left.\phi_{\text {eff }}\right)$ at each operation mode.

Figure 17. Effect of EGR rate over the cylinder pressure and RoHR profile at each operation mode.

Figure 18. Effect of EGR rate over combustion phase (CA10 and CA50), dP/d $\alpha_{\max }, \mathrm{P}_{\max }, \mathrm{CoV} \mathrm{P}_{\max }$ and COV IMEP at each operation mode. 
Figure 19. Effect of EGR rate over particle size distributions (PSD) and PN emissions at each operation mode.

Figure 20. Effect of CA50 and Pmax over the GMDs at each operation mode, during the EGR rate variations.

Figure 21. Effect of EGR rate over ISFC and ISFC $_{\text {corr }}$ at each operation mode.

Figure 1.

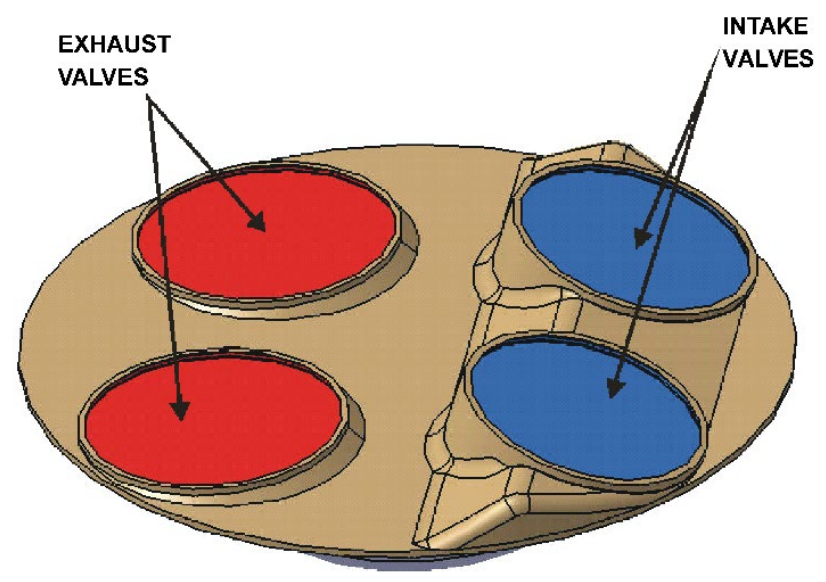

Figure 2.

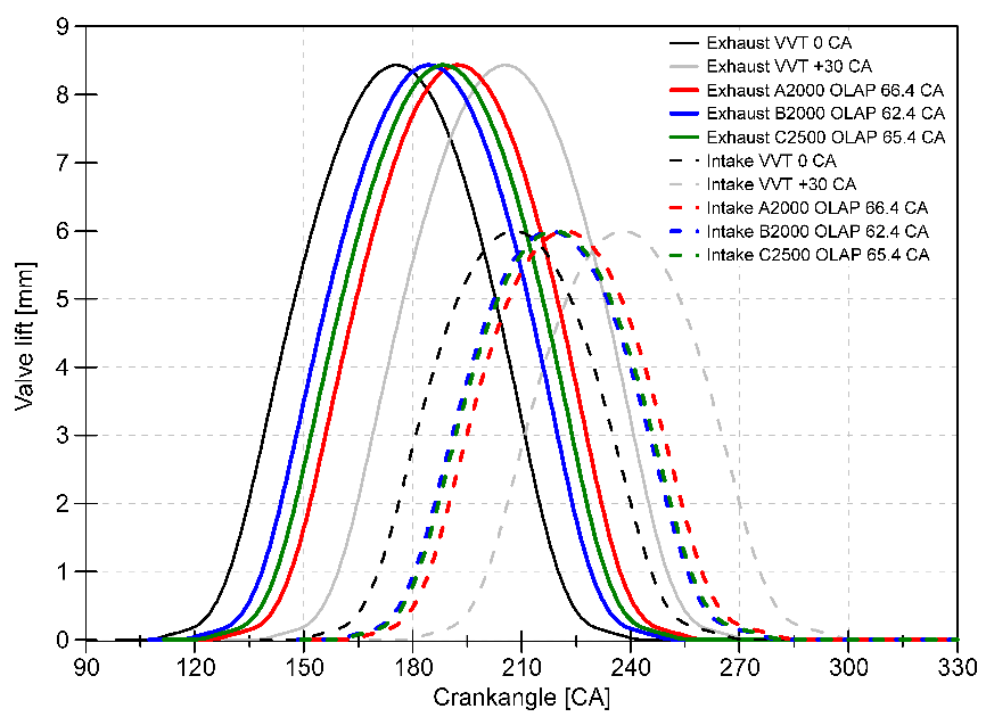


Figure 3.

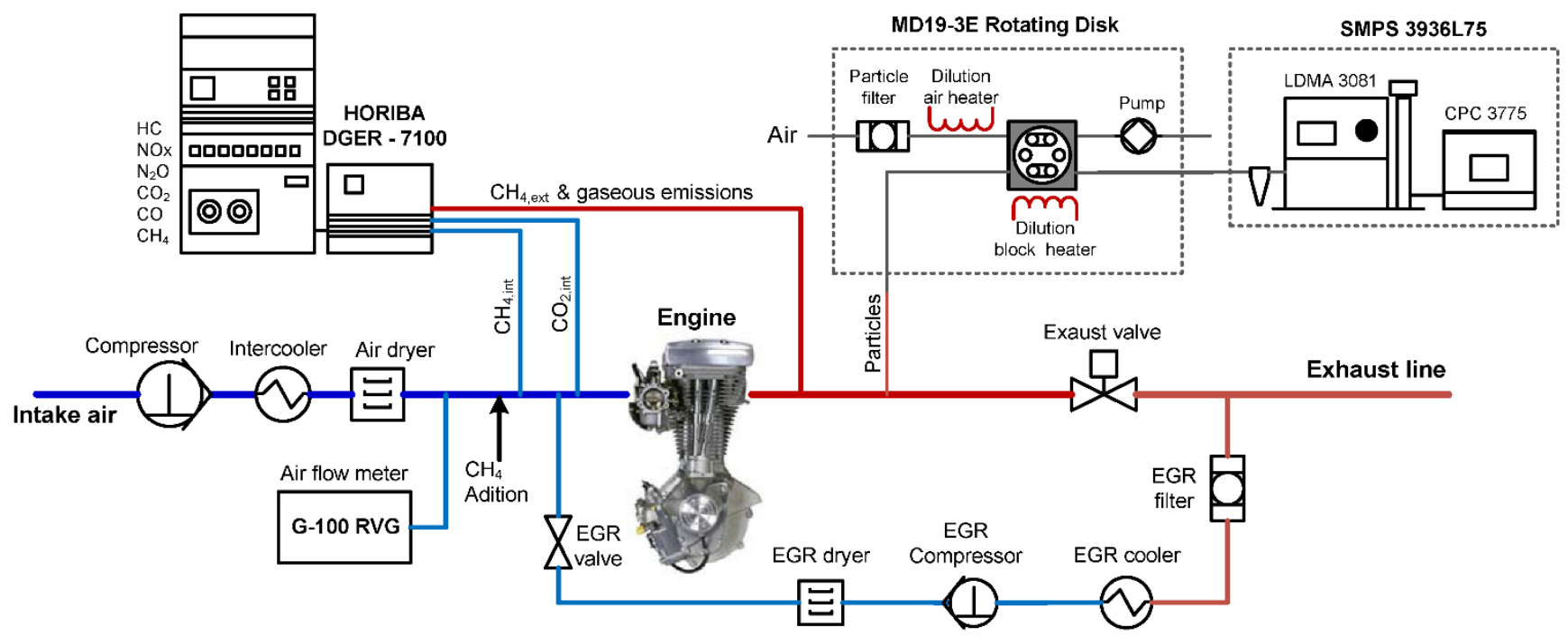

Figure 4.
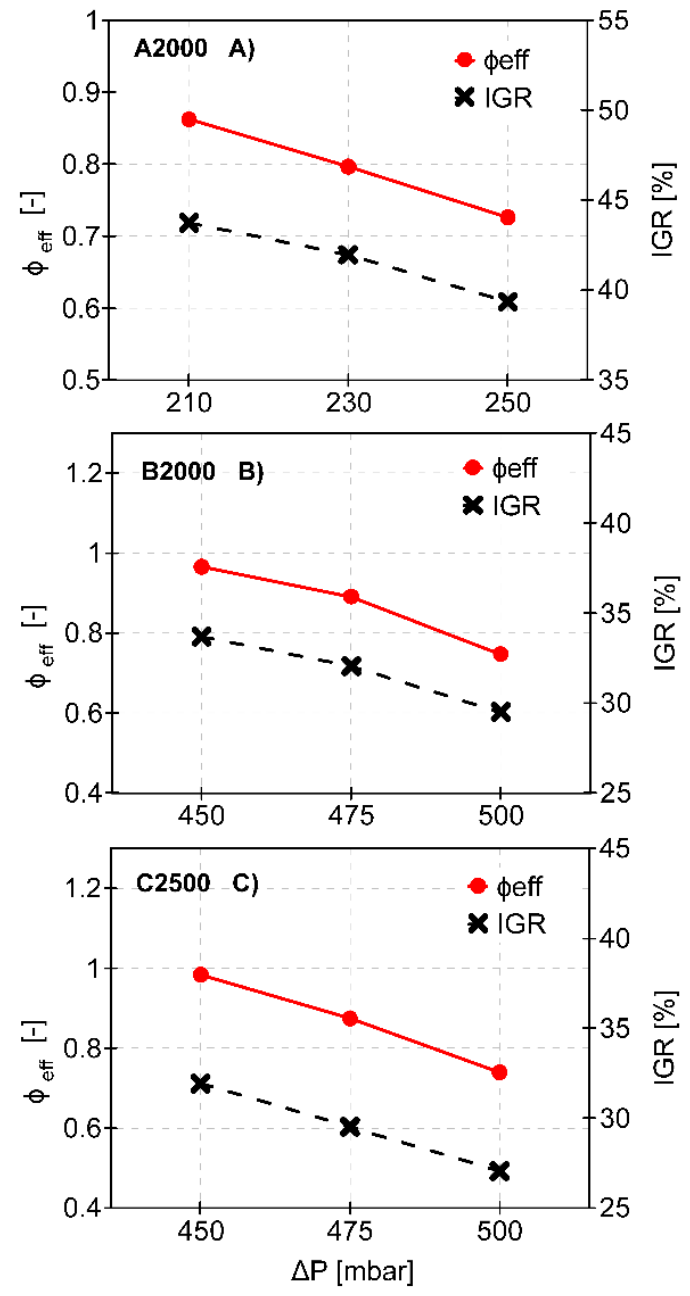

Figure 5. 


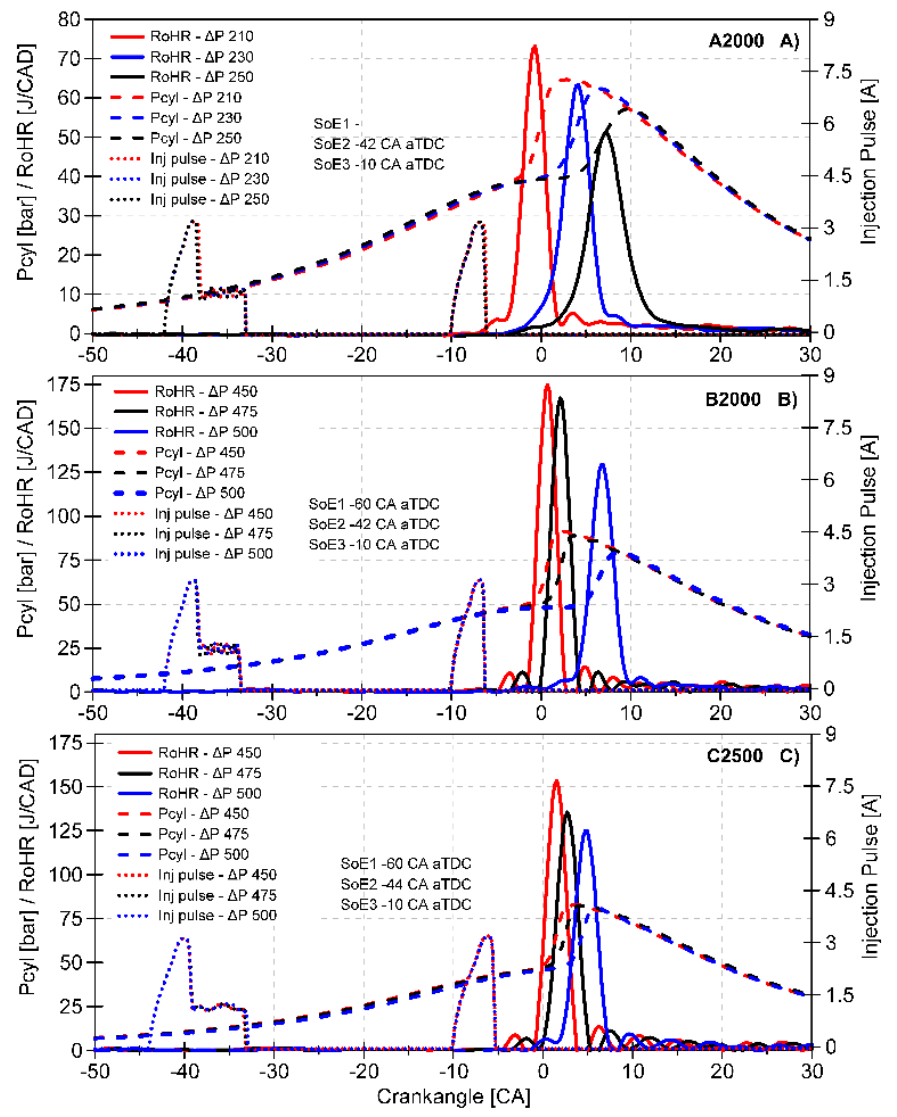

Figure 6.

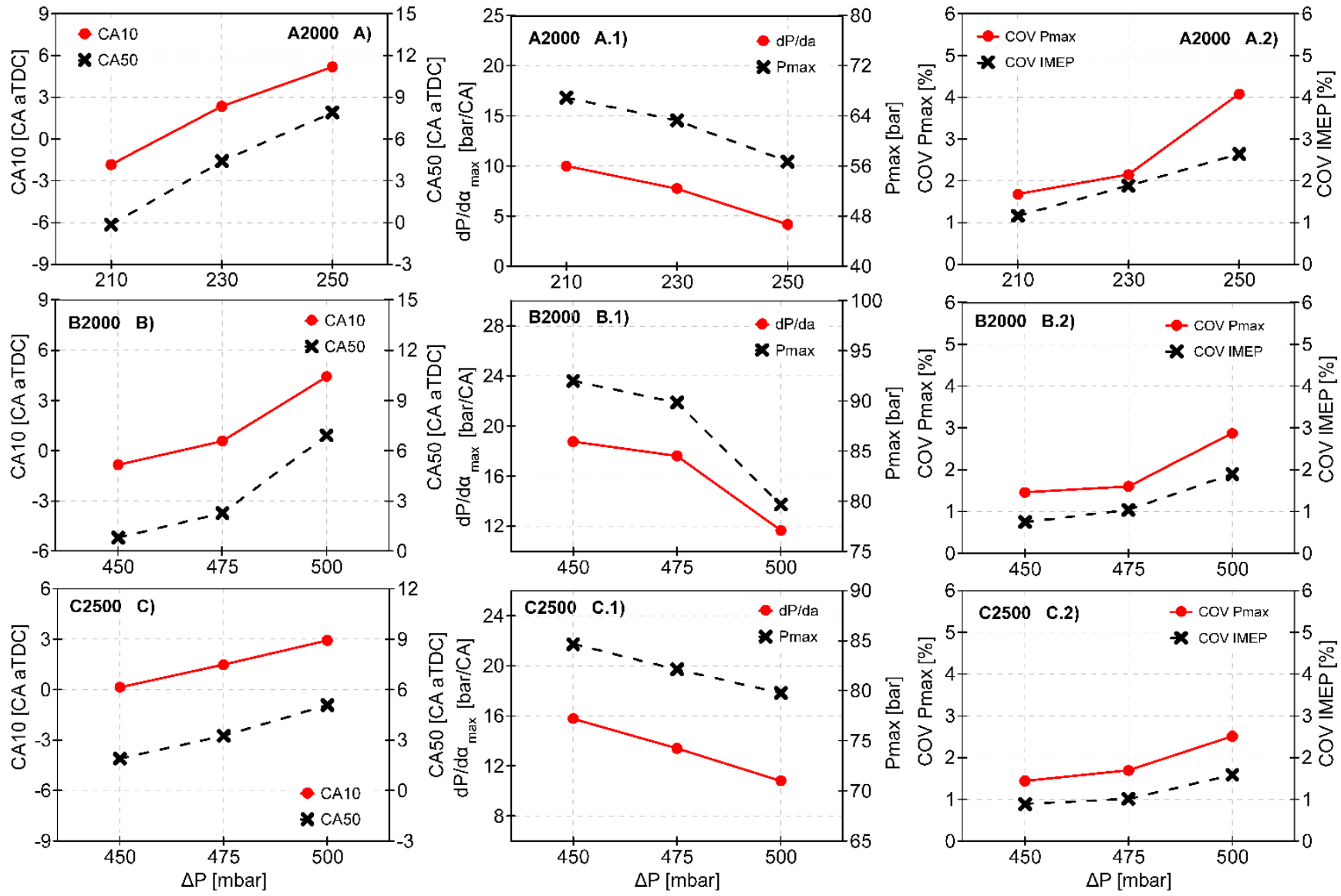


Figure 7.
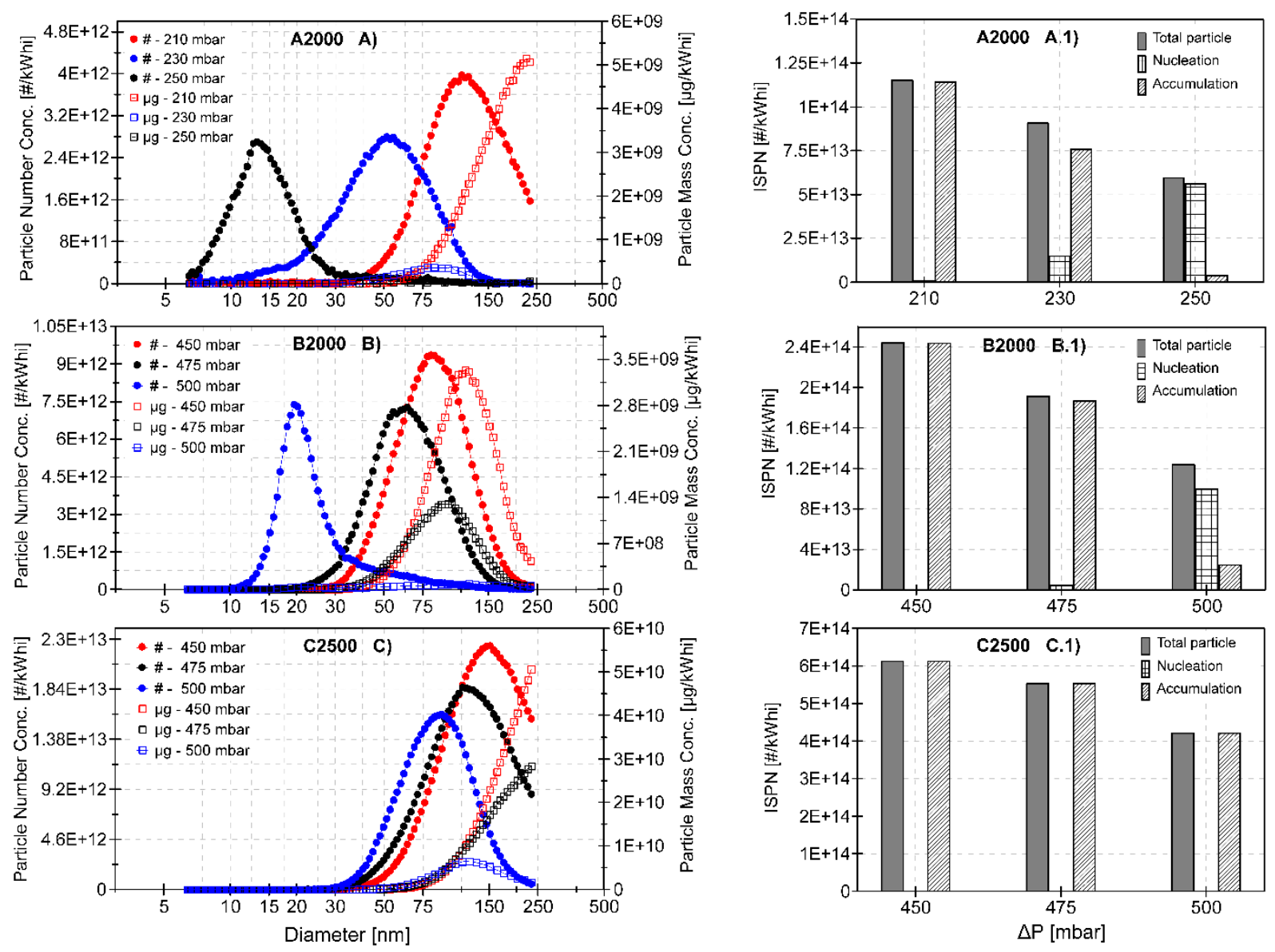

Figure 8.

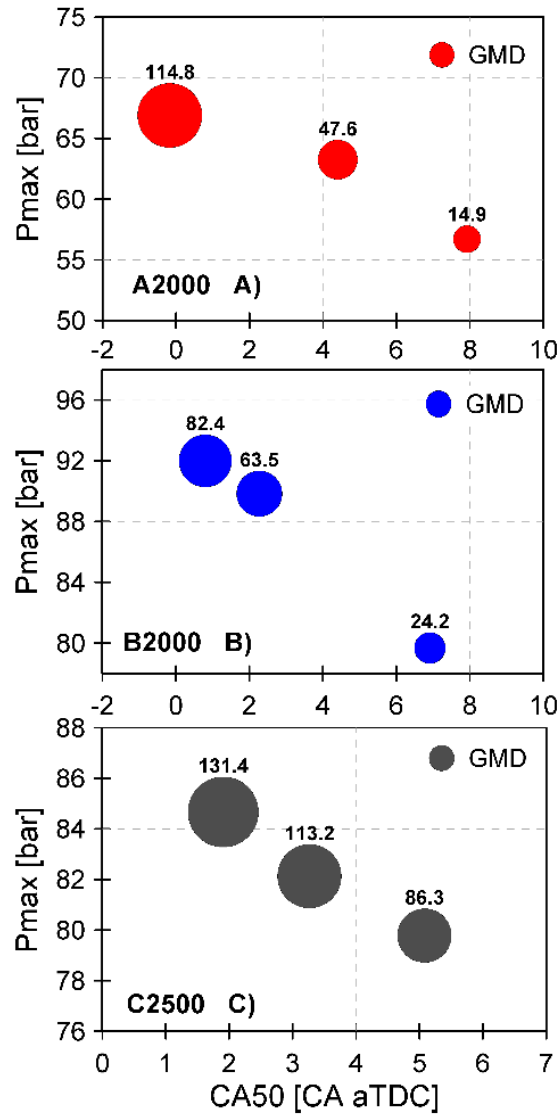


Figure 9.
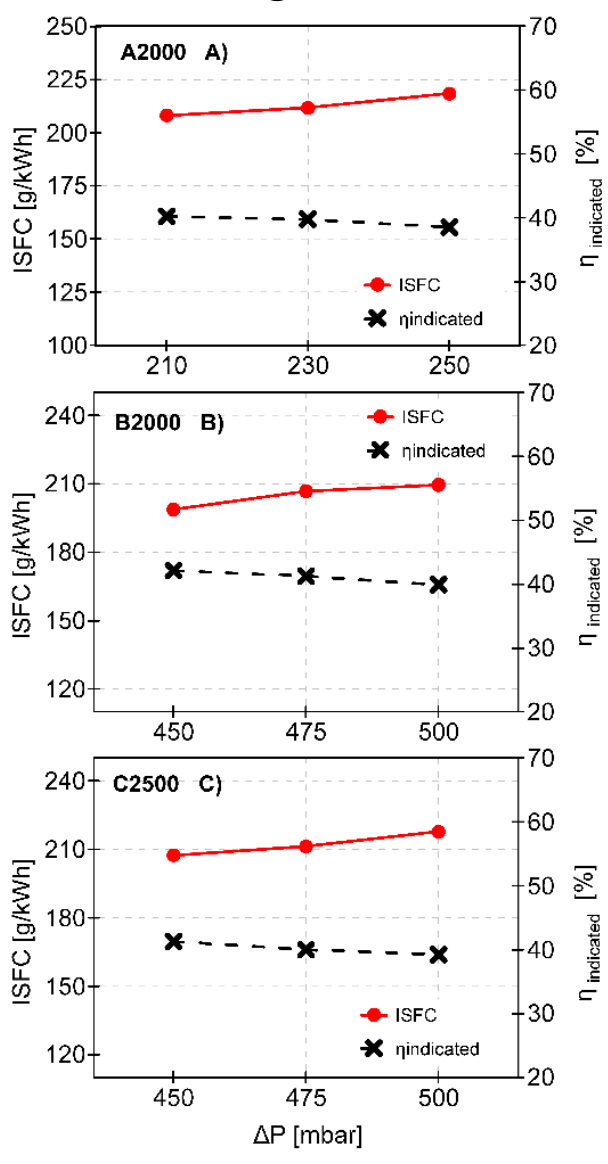

Figure 10.

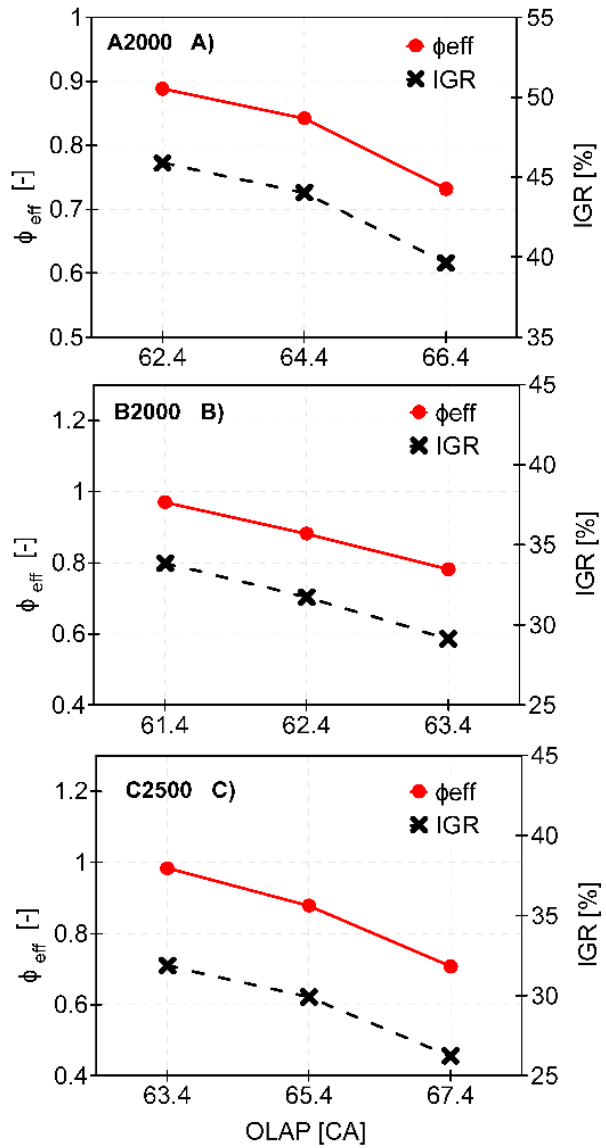


Figure 11.
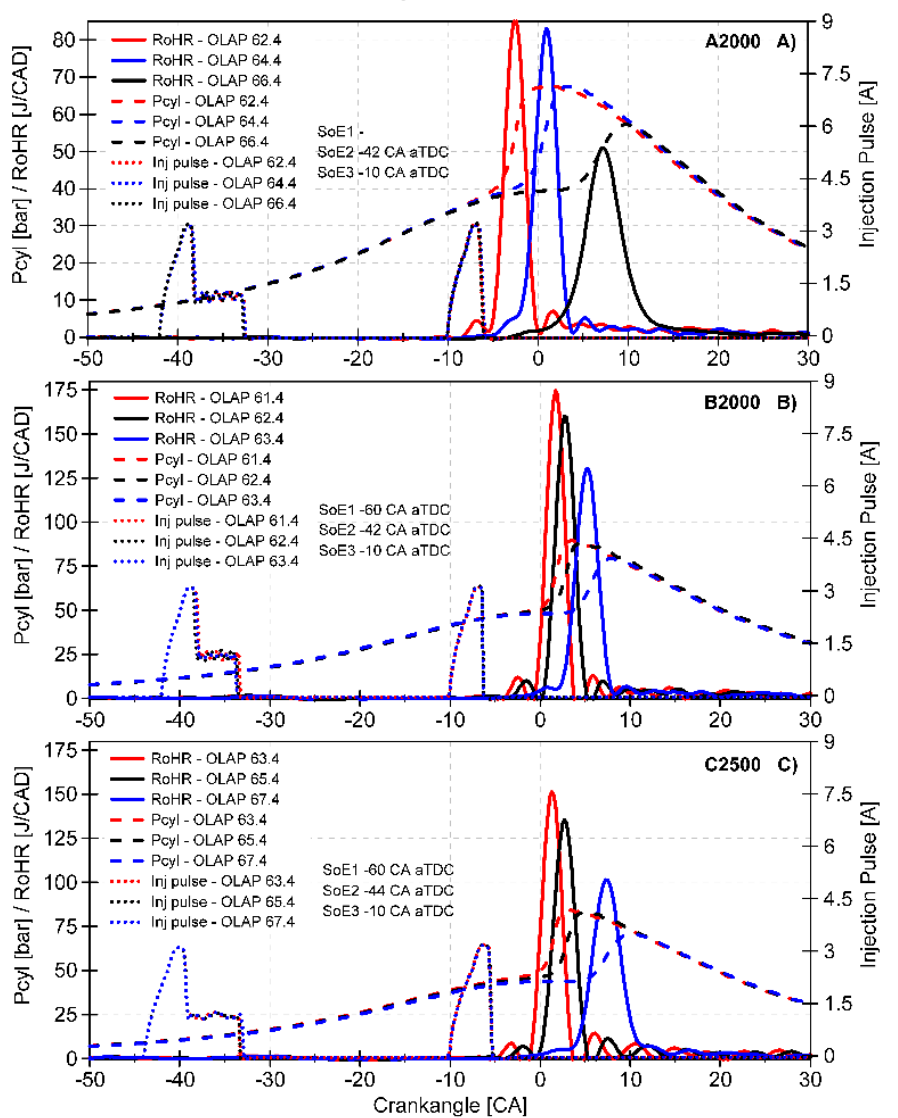

Figure 12.
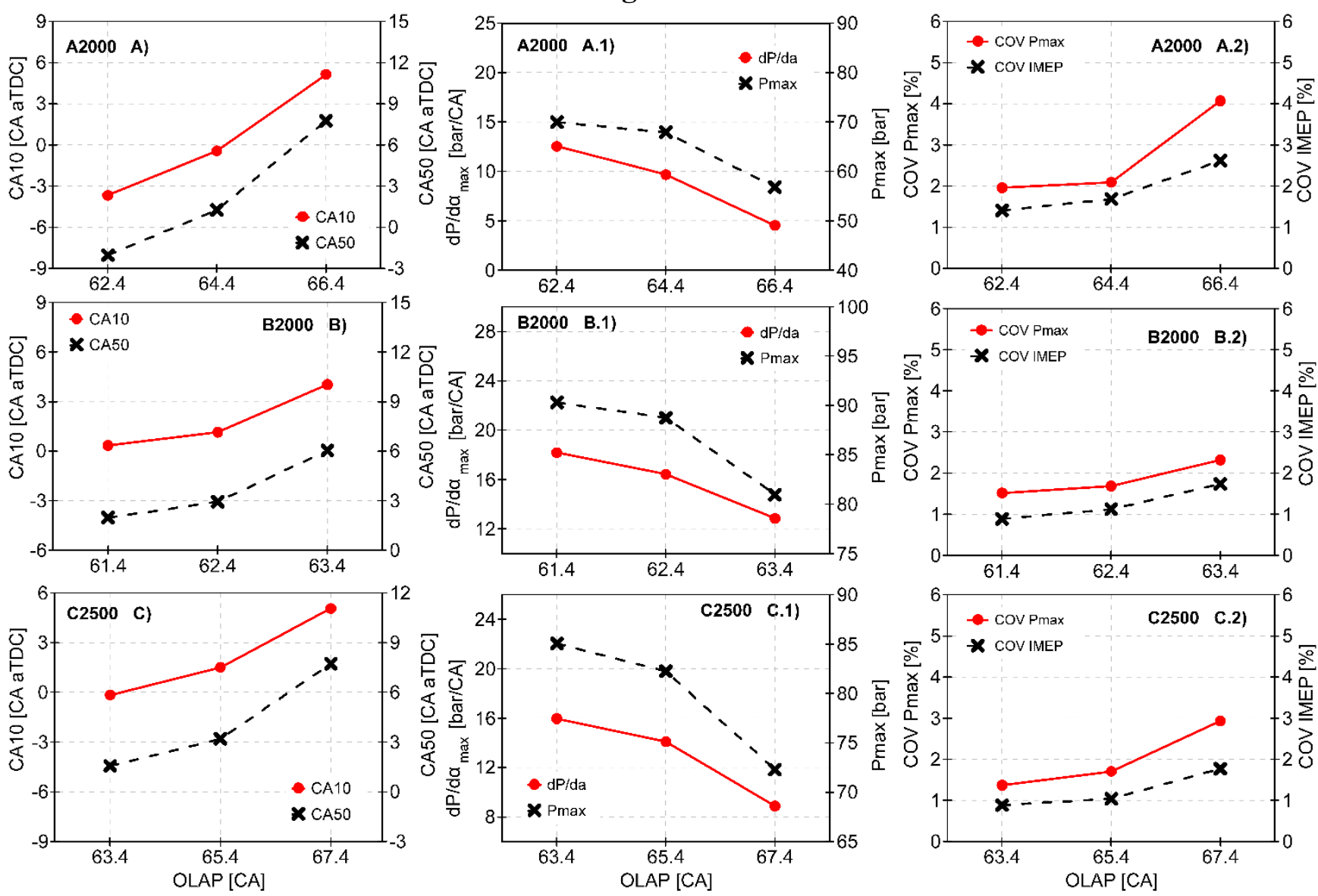
Figure 13.
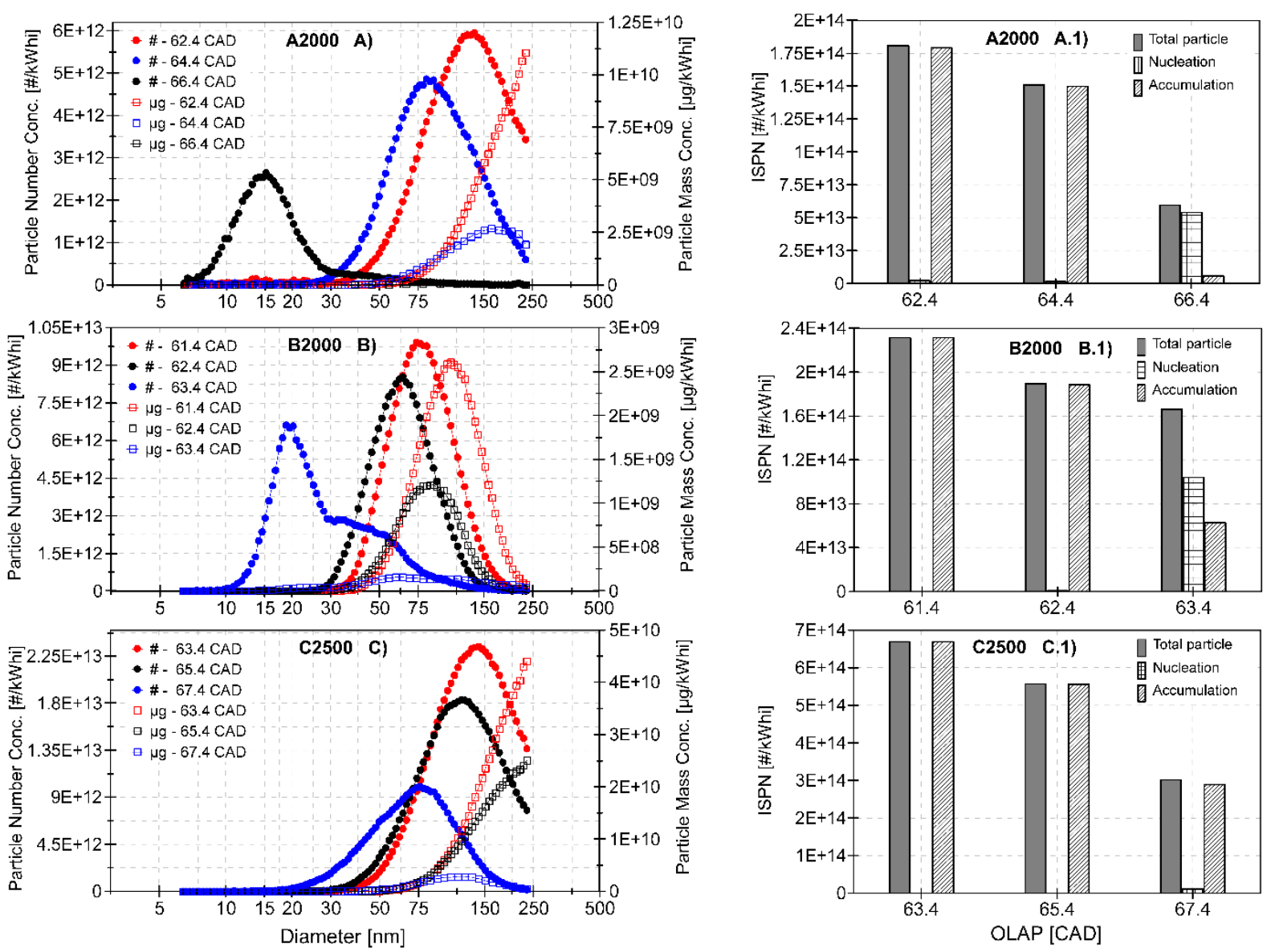

Figure 14.
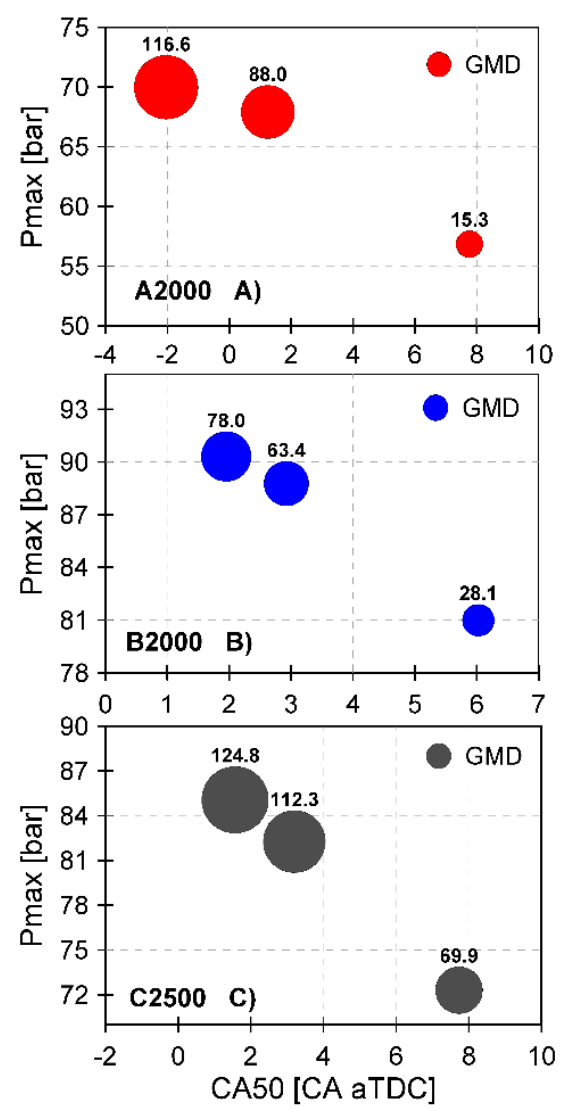
Figure 15.
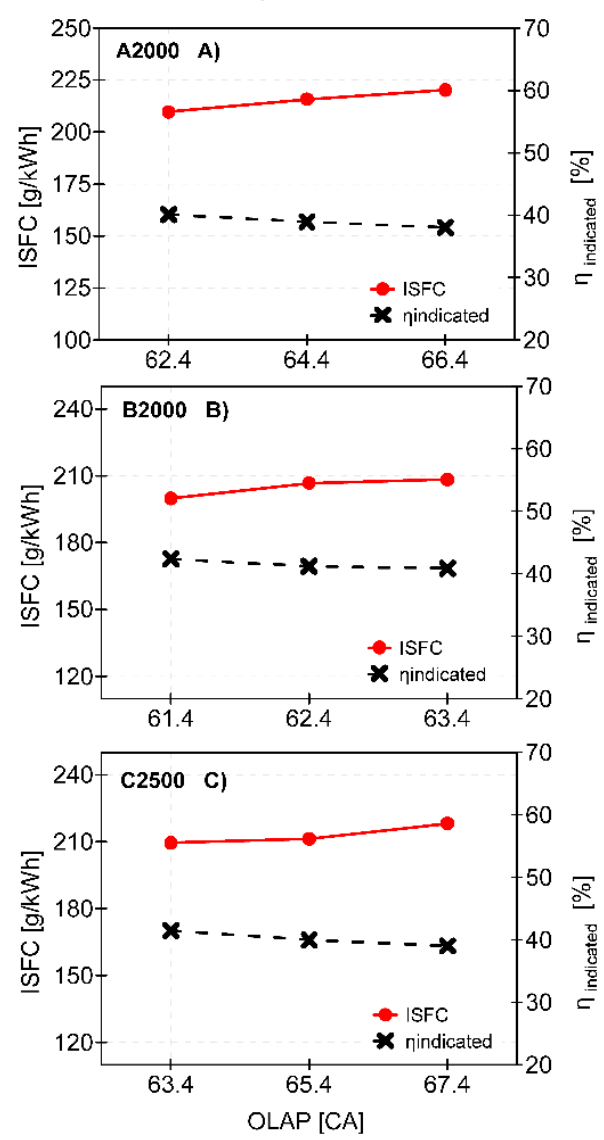

Figure 16.

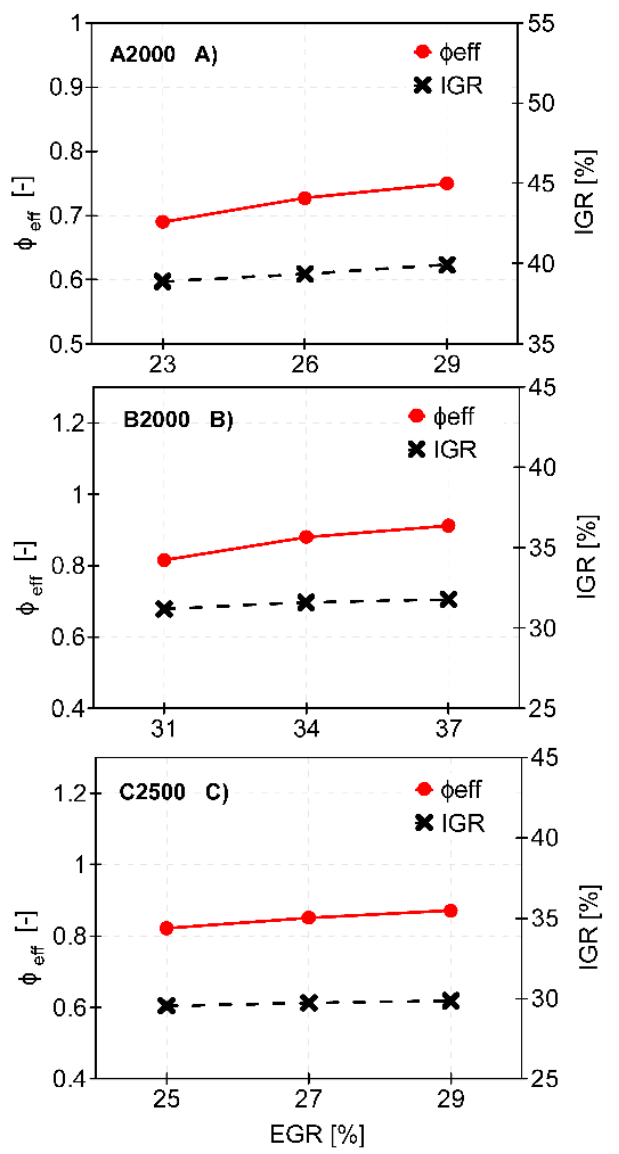


Figure 17.
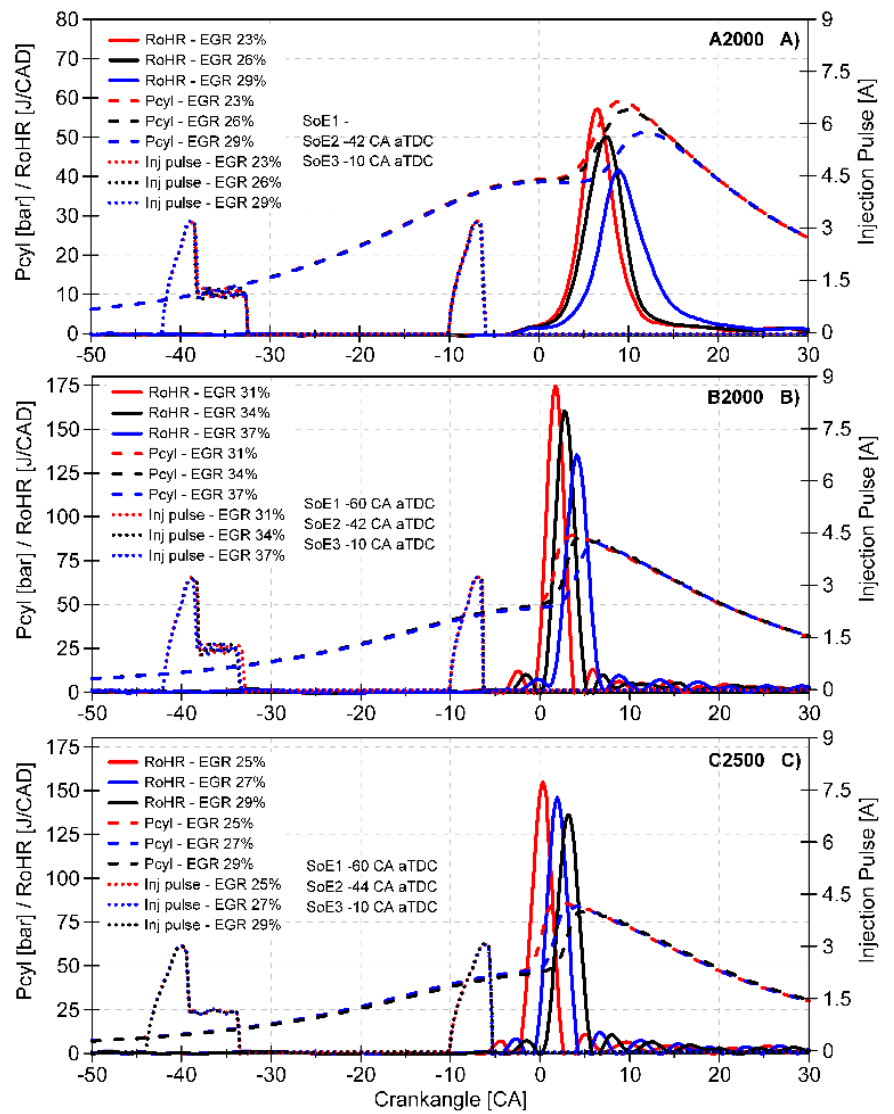

Figure 18.

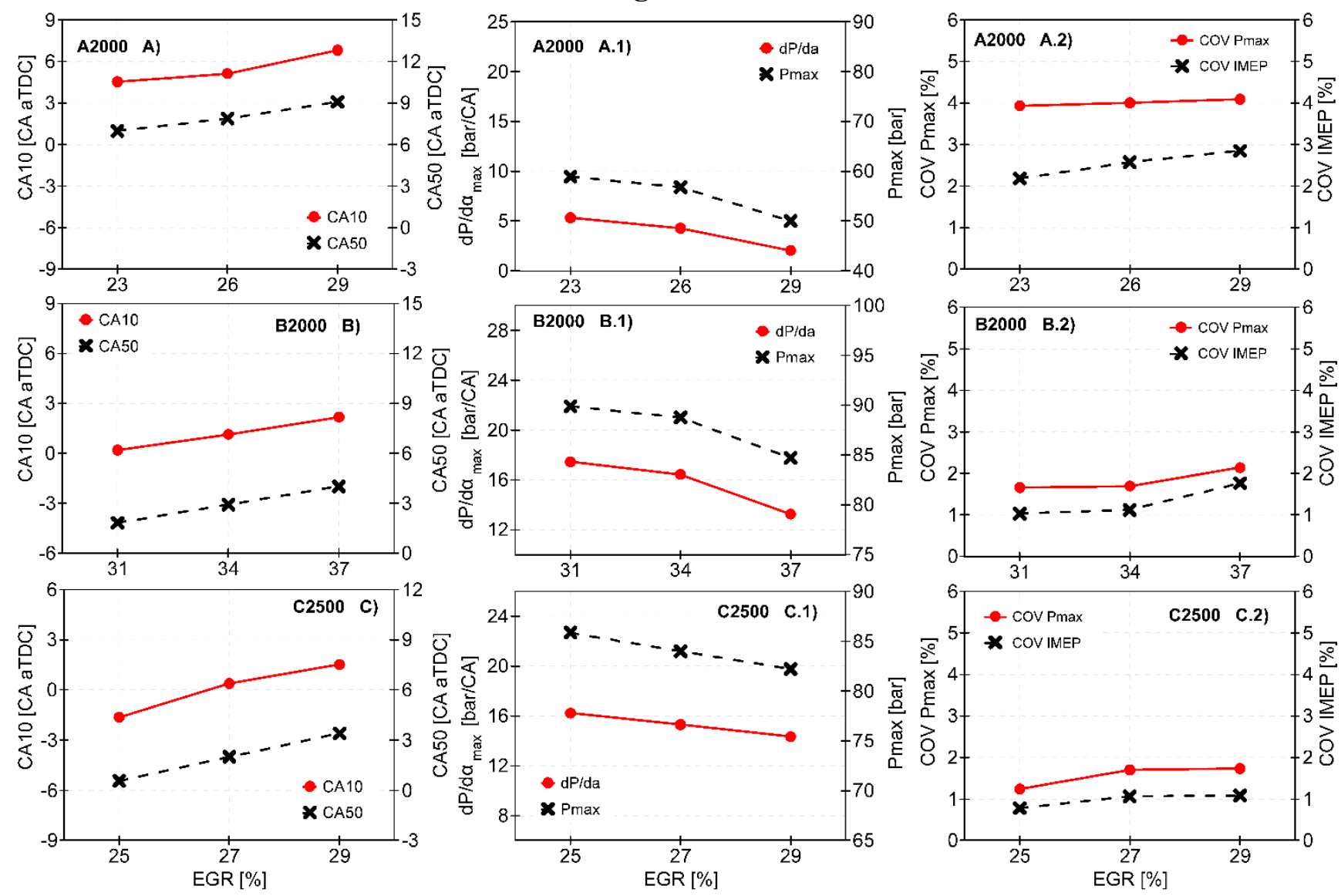


Figure 19.
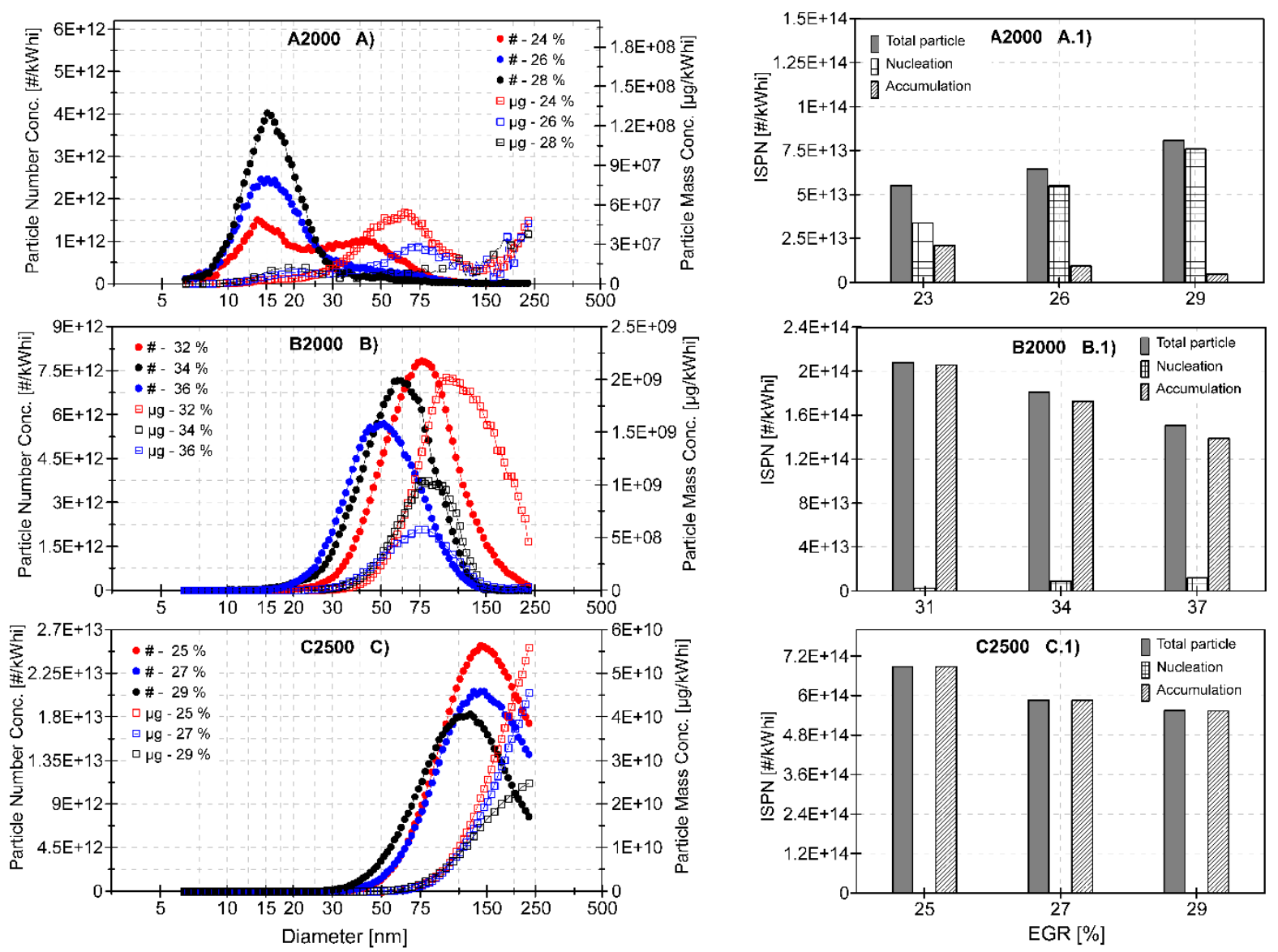

Figure 20.

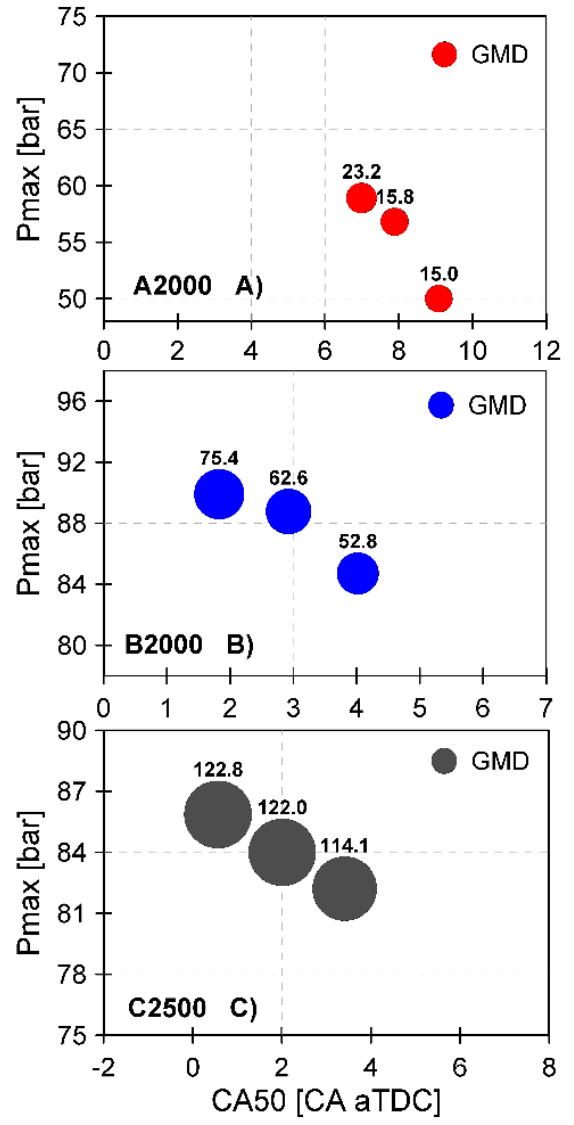


Figure 21.
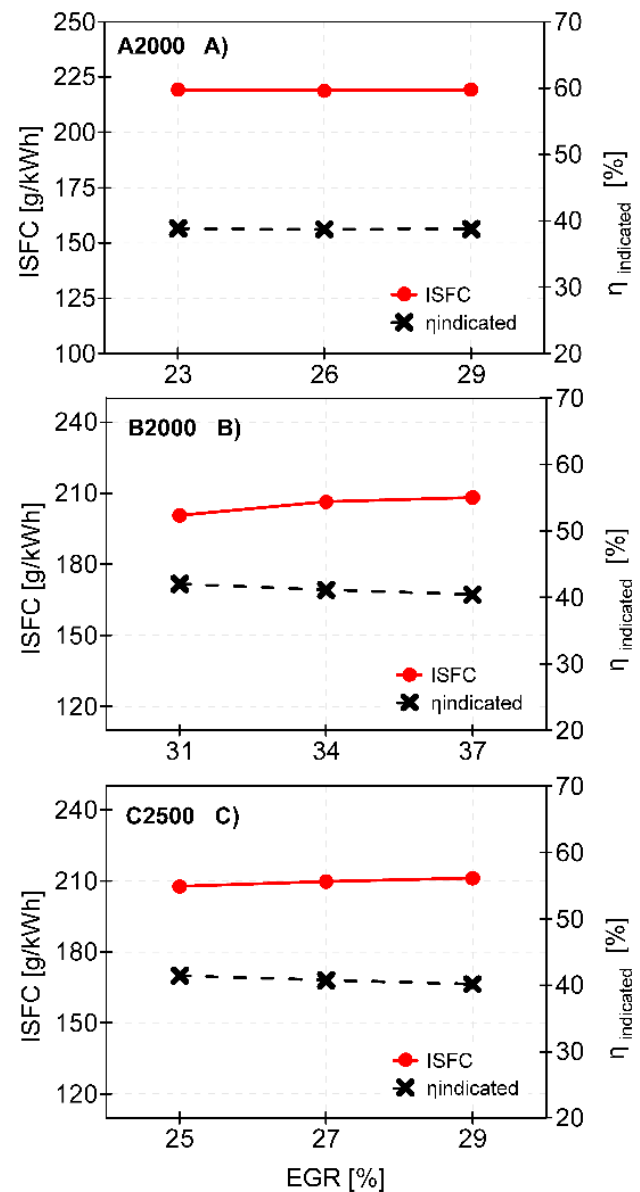